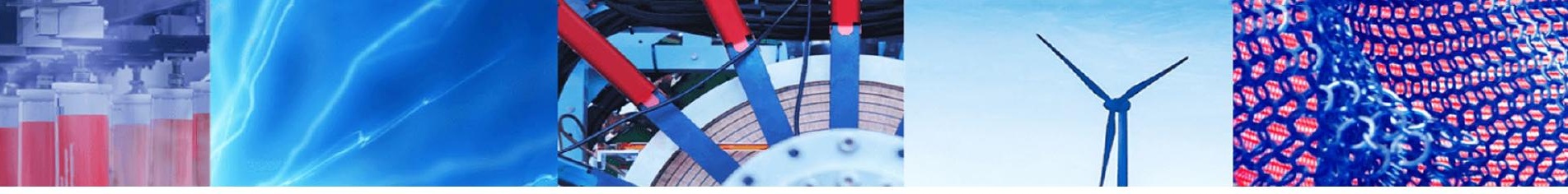

Review Paper

\title{
Recent advances in ultraprecision abrasive machining processes
}

\author{
M. J. Jackson ${ }^{1}$ (1)
}

Received: 19 December 2019 / Accepted: 29 May 2020 / Published online: 5 June 2020

(c) Springer Nature Switzerland AG 2020

\begin{abstract}
Traditional approaches to understanding ultraprecision machining processes such as grinding, polishing, lapping, micromachining, machining, etc., have focused on developing analytical, semi-empirical and empirical models that seek to explain the output of processes based on many input variables. However, those models are not very well suited to providing inputs to develop improved abrasive products such as grinding wheels, lapping wheels, honing laps, coated abrasives, loose abrasives and their associated bonding systems and lubricants. In order to develop new products to improve ultraprecision processing of materials, it is necessary to focus on the mechanisms of microscopic interactions between abrasive products and the workpiece material. This paper reviews the current grinding theories and the methods employed to understand microscopic interactions due to cutting, plowing and sliding motions and how they can be used to develop new products using materials science principles that enhance and uniquely describe the removal of material in ultraprecision machining processes.
\end{abstract}

Keywords Materials $\cdot$ Cutting $\cdot$ Tribology $\cdot$ Interactions $\cdot$ Ultraprecision $\cdot$ Machining $\cdot$ Materials

\section{Introduction}

When considering microscopic interactions during the abrasive machining process based on forces, power and energy expended, computational techniques are required that directly measure the output of an ultraprecision machining process such as grinding (or abrasive machining) in order to fully ascertain which aspect of cutting, plowing and sliding are required to be utilized to generate the manufacturing cycle. With the advent of advanced computing techniques and the development of more sophisticated instrumentation associated with industry 4.0 concepts, the measurement of tribological interactions during ultraprecision processing is becoming a practical reality and will be needed if we are to realize true precision at the nano and pico length scales.

The high strain rates experienced in ultraprecision grinding processes creates a deformation zone within a very thin plane depending on the thickness of the cut chip
[1-3]. The defined geometry of the abrasive grits form a new surface and the shear strain rates are between $10^{7}$ and $10^{8} \mathrm{~s}^{-1}[4]$ and this causes plowing and/or sliding between abrasive and workpiece to dominate. The process of grinding can best be described as plowing with a very shallow depth of penetration that is accompanied by very high contact stresses with subsequently high normal forces that creates microcracks on the surfaces coupled with much smaller tangential forces that creates the chips from precracked surfaces. If the bonding system interferes with chip formation, then rubbing and plowing remain dominant during grinding. A reduction in the amount of bond and the geometrical size of the bond bridges will promote cutting rather than tribological interactions such as rubbing and plowing. Currently, there are six predominant interactions between wheel and workpiece. These are: (1) Abrasive/workpiece interactions: 1.1 cutting (machining, $\mu>1$ when chip formation is dominant rather than $\mu<1$ which implies that surface crack formation is dominant),

M. J. Jackson, mjjackson@ksu.edu| ${ }^{1}$ School of Integrated Studies, College of Technology and Aviation, Kansas State University, Salina, KS 67401, USA.

SN Applied Sciences (2020) 2:1172 | https://doi.org/10.1007/s42452-020-2982-y 
1.2 plowing (material deformation, $\mu \sim 0.5$ to 1 ) and 1.3 sliding ( $\mu \sim 1 / 6)$; (2) chip and bond sliding ( $\mu \sim 0.3$ to 0.5 ); (3) chip and workpiece sliding ( $\mu \sim 0.3$ to 0.5 ); and (4) bond and workpiece sliding ( $\mu \sim 0.3$ to 0.5 ) (Fig. 1).

Compared to traditional single point cutting operations, the grinding grit cuts the material then becomes blunt as time progresses creating a grit that plows and slides along the surface modifying the structure of the material in an uncontrolled manner. The ability to control these effects, both cutting and tribological, is at the heart of ultraprecision machining processes. If machining and surface modification can be balanced during the grinding cycle then the microscopic interactions shown in Fig. 1 can be complemented by the truing and dressing procedures, coolant application, and cycle design to produce a manufacturing envelope that satisfies the user in terms of producing highly precise products in an acceptable time frame. This type of activity is fast becoming known as, 'grinding science' by some authors and 'material removal science for abrasive machining' by others, and is heavily dependent upon developing materials for both abrasive grits and bonding systems that respond to operational parameters during the grinding cycle. The science of cutting and abrasion are well understood separately, but there is a growing need to understand how these two areas of science work together in a synergistic manner in order to realize ultra-precision processing at micro, nano and pico scales. In addition to this understanding, advances in materials science discoveries need to focus on product development so that measured parameters can be related to microscopic and sub-microscopic interactions that are then integrated into the product development cycle.

\section{Tribological interactions in ultraprecision machining processes}

The literature is well documented when it comes to understanding the process of ultraprecision machining since the 1950 s by researchers in the United States of America such as Hahn, Lindsey, Malkin, Subramanian, et al. [1-10]. However, tribological interactions and models have been treated separately, or treated as a lumped parameter during this time owing to the complexity of fully understanding their role during ultraprecision machining processes such as grinding. Malkin and Guo [8] describe the current models of grinding that have been developed from an academic and a semiacademic viewpoint to describe the grinding process as a series of equations using lumped parameters. The models and their associated equations are shown in Table 1.

The models are arranged in Table 1 to show the relevant equation and a physical description of the model for each lumped parameter. For instance, the total grinding force model [7] is generally described using the equation:

$F_{\text {total }}=F_{\text {chip }}+F_{\text {sliding }}+F_{\text {plowing }}$

where $F_{\text {total }}$ is the total grinding force, $F_{\text {chip }}$ is the chip formation force, $F_{\text {sliding }}$ is the sliding force and $F_{\text {plowing }}$ is the plowing force. It must be remembered that the component forces in the normal and tangential direction are given by:

$F_{n}=F_{\text {nchip }}+F_{\text {nsliding }}+F_{\text {nplowing }}$ (a)

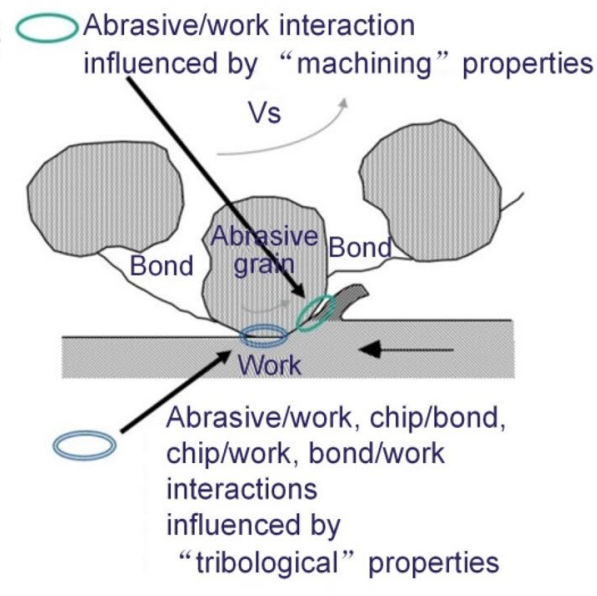

(b)

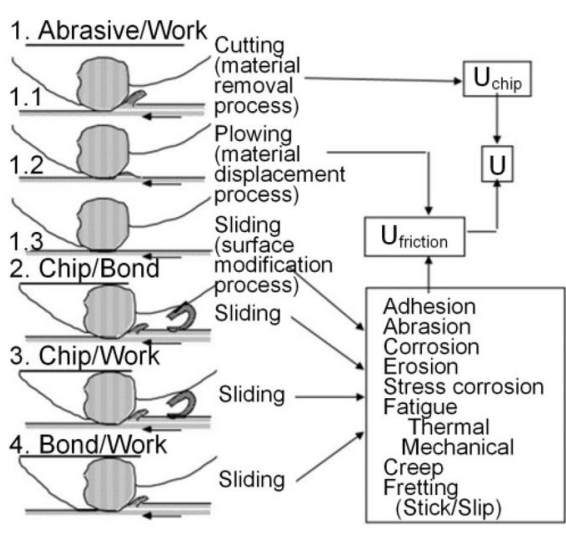

Interactions in the Grinding Zone:

\begin{tabular}{|ll|}
\hline \multicolumn{2}{|c|}{ Ft/Fn } \\
1.1 & $>1.0$ \\
1.2 & 0.5 to 1.0 \\
1.3 & $1 / 6(=0.165)$ \\
2 & 0.3 to 0.5 \\
3 & 0.3 to 0.5 \\
4 & 0.3 to 0.5 \\
\hline
\end{tabular}

Fig. 1 Grinding wheel and workpiece interactions showing a elements of cutting, plowing and sliding and $\mathbf{b}$ de-composed interactions showing sub-classifications of sliding interactions and associ- ated force ratios $\left(\mu=F_{t} / F_{n}\right)$. Adapted from drawings provided by $D r$. Michael Hitchiner and Dr. Subramanian, Saint-Gobain Abrasives, Worcester, Massachusetts, USA 
Table 1 Grinding models according to Malkin and Guo [8]. Images courtesy of Professor Malkin and presented at the Saint-Gobain Grinding Symposium, 8th November 2012

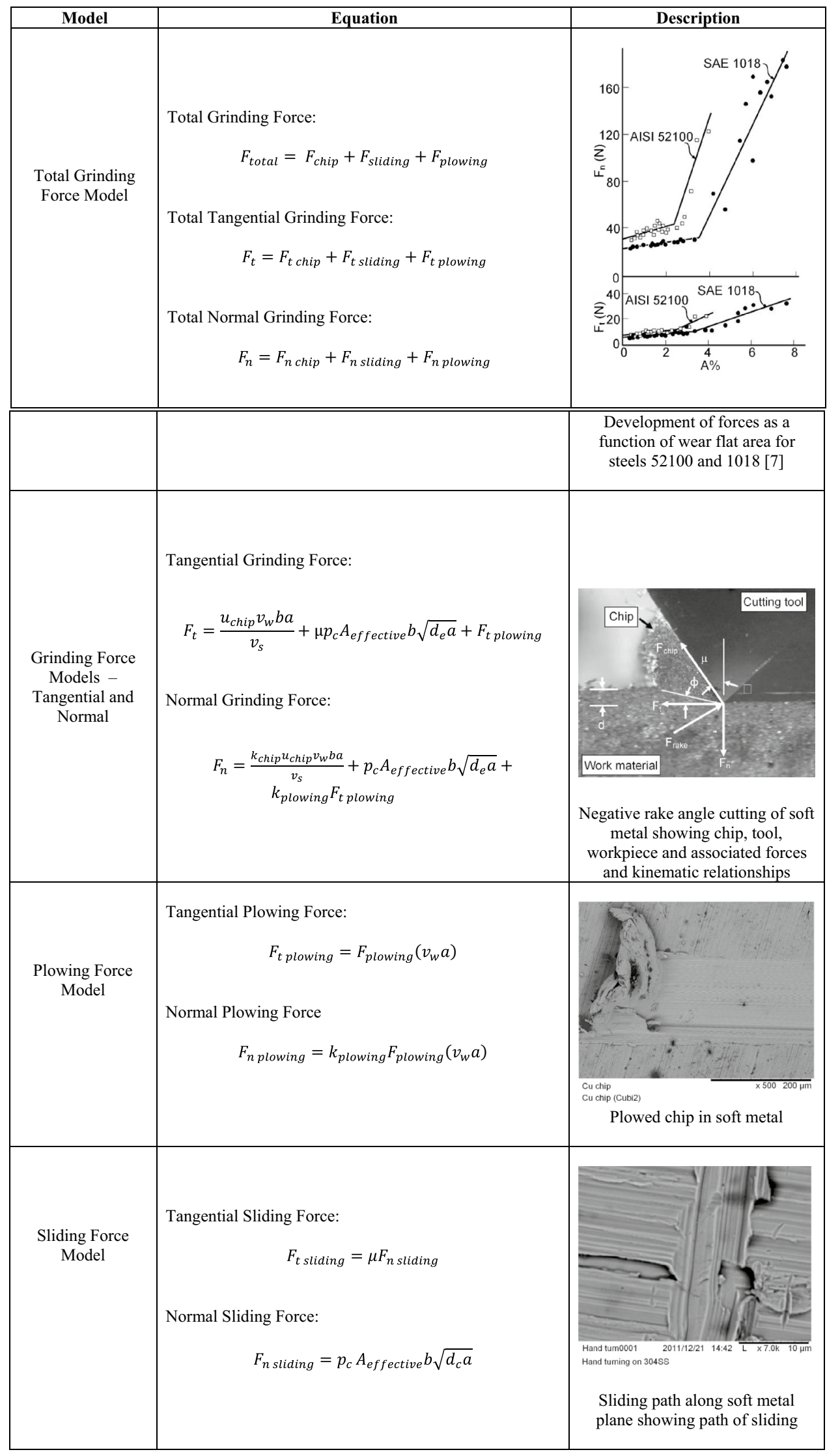


Table 1 (continued)

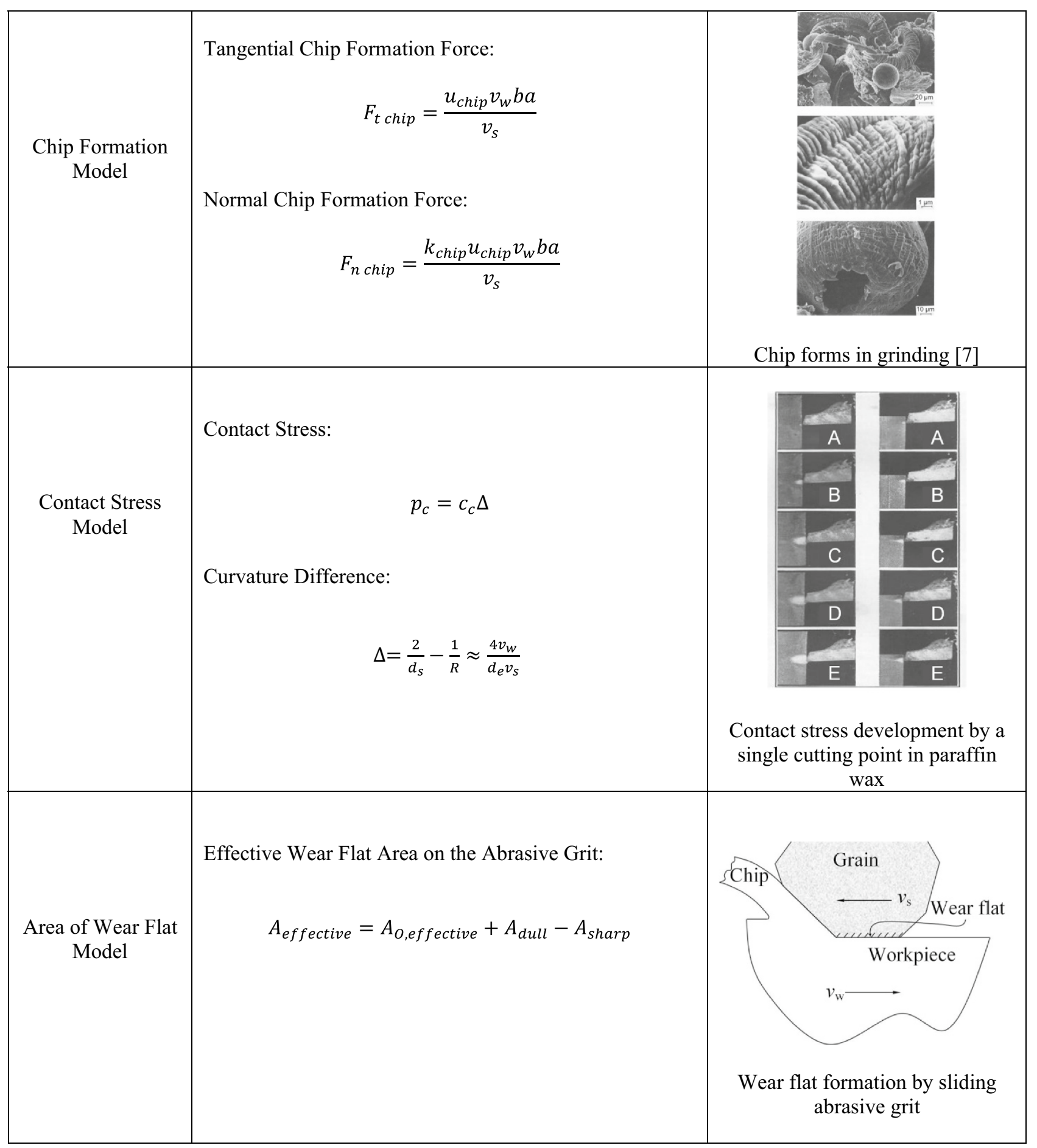

$F_{t}=F_{\text {tchip }}+F_{\text {tsliding }}+F_{\text {tplowing }}$

Where Eqs. 2 and 3 refer to the normal and tangential components of force, respectively. The increase in forces is a function of the wear flat area that is generated on the surface of the active cutting edges and the description of force behavior for a number of engineering steels is shown by Malkin [7]. When considering the individual parts of Eqs. 1-3, the models can be further analyzed in terms of their dependent variables. If we consider tangential and normal forces, we find that the tangential and normal force is dependent on the chip formation energy, $u_{\text {chip, }}$ work speed, $v_{w}$, wheel speed, $v_{s}$ grinding width, $b$, depth of cut, $a$, contact stress, $p_{c^{\prime}}$ effective wear flat area, $A_{\text {effective' }}$ 
Table 1 (continued)

\begin{tabular}{|c|c|c|}
\hline $\begin{array}{l}\text { Empirical Wear } \\
\text { Flat Area Model }\end{array}$ & $\begin{array}{l}\text { Empirical Wear Flat Area: } \\
\qquad A_{O, \text { effective }}=-A_{O} \ln \left(\frac{A_{1} \delta}{f(w)}\right) \\
\text { Dressing Severity Parameter: } \\
\qquad \delta=a_{O} s_{d}^{1.75} a_{d}^{0.75}\end{array}$ & $\begin{array}{l}\text { (2) } \\
\text { Wear flats generated on the } \\
\text { surface of a grinding wheel [7] }\end{array}$ \\
\hline $\begin{array}{c}\text { Wear Flat Dulling } \\
\text { Area Model }\end{array}$ & $A_{\text {dull }}=k_{l} l_{\text {sliding }}$ & $\begin{array}{l}\text { Wear flat on individual abrasive } \\
\text { grits }\end{array}$ \\
\hline $\begin{array}{c}\text { Sliding Length } \\
\text { Model }\end{array}$ & $l_{\text {sliding }}=\int_{0}^{t} \frac{v_{s} l_{c}}{\pi d_{s}} d t$ & $\begin{array}{l}\text { gptical microscope arrangement } \\
\text { to measure wear flat area between } \\
\text { grinding cycles }\end{array}$ \\
\hline $\begin{array}{c}\text { Specific Energy } \\
\text { and Power Models }\end{array}$ & $\begin{array}{l}\text { Specific Energy Model (Energy/Volume): } \\
\qquad u=u_{\text {chip }}+u_{\text {sliding }}+u_{\text {plowing }} \\
\text { Grinding Power: }\end{array}$ & \\
\hline
\end{tabular}


Table 1 (continued)

\begin{tabular}{|c|c|c|}
\hline & $P=P_{\text {chip }}+P_{\text {sliding }}+P_{\text {plowing }}=F_{t} v_{s}$ & Specific energy relationship for \\
\hline $\begin{array}{l}\text { Chip Formation } \\
\text { Energy/Power } \\
\text { Model }\end{array}$ & $\begin{array}{l}\text { Chip Formation Energy: } \\
\qquad u_{c h i p}=\frac{F_{t c h i p} v_{s}}{b v_{s} a} \\
\text { Power Required for Chip Formation: } \\
\qquad P_{\text {chip }}=u_{c h i p} v_{w} b a\end{array}$ & $\begin{array}{c}\qquad \mathrm{u}_{\mathrm{ch}}=13.8 \mathrm{~J} / \mathrm{mm}^{3} \\
\mathrm{v}_{\mathrm{w}} \mathrm{a}\left(\mathrm{mm}^{2} / \mathrm{s}\right) \\
\begin{array}{c}\text { Chip formation energy } \\
\text { characteristic }\end{array}\end{array}$ \\
\hline $\begin{array}{l}\text { Plowing Power, } \\
\text { Sliding Power and } \\
\text { Total Power } \\
\text { Models }\end{array}$ & 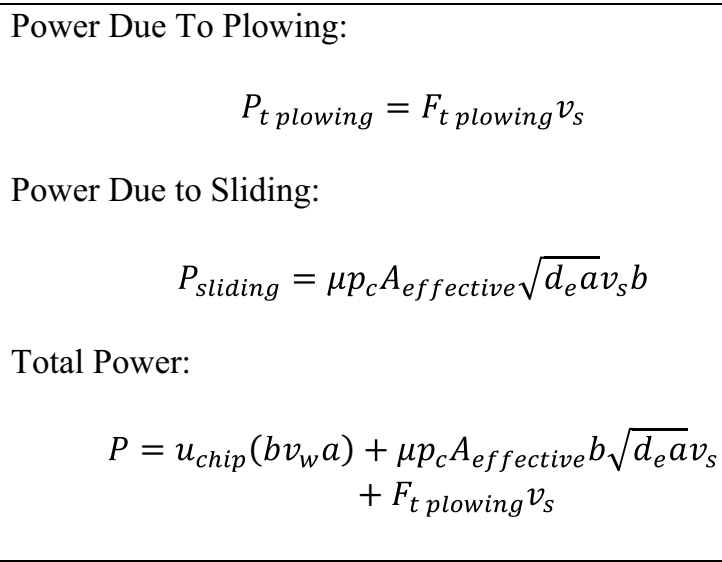 & $\begin{array}{c}\text { Removal rate } \\
\text { Plowing force as a function of } \\
\text { MRR }\end{array}$ \\
\hline $\begin{array}{l}\text { Maximum } \\
\text { Temperature } \\
\text { Model }\end{array}$ & $\theta_{\text {maximum }}=\frac{1.13 q_{w} \sqrt{\alpha} a^{0.25} d_{e}^{0.25}}{k \sqrt{v_{w}}}$ & \\
\hline
\end{tabular}


Table 1 (continued)

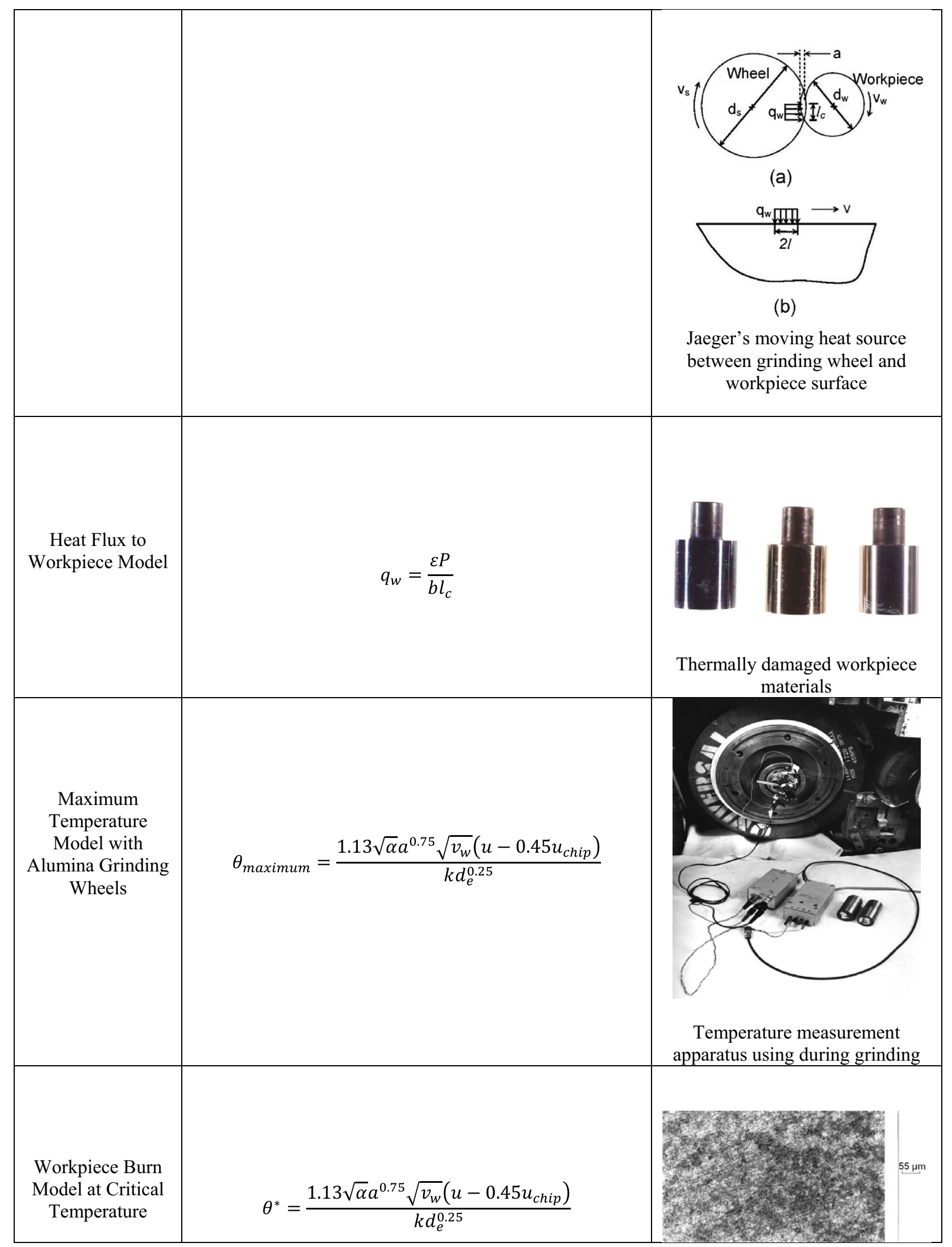


Table 1 (continued)

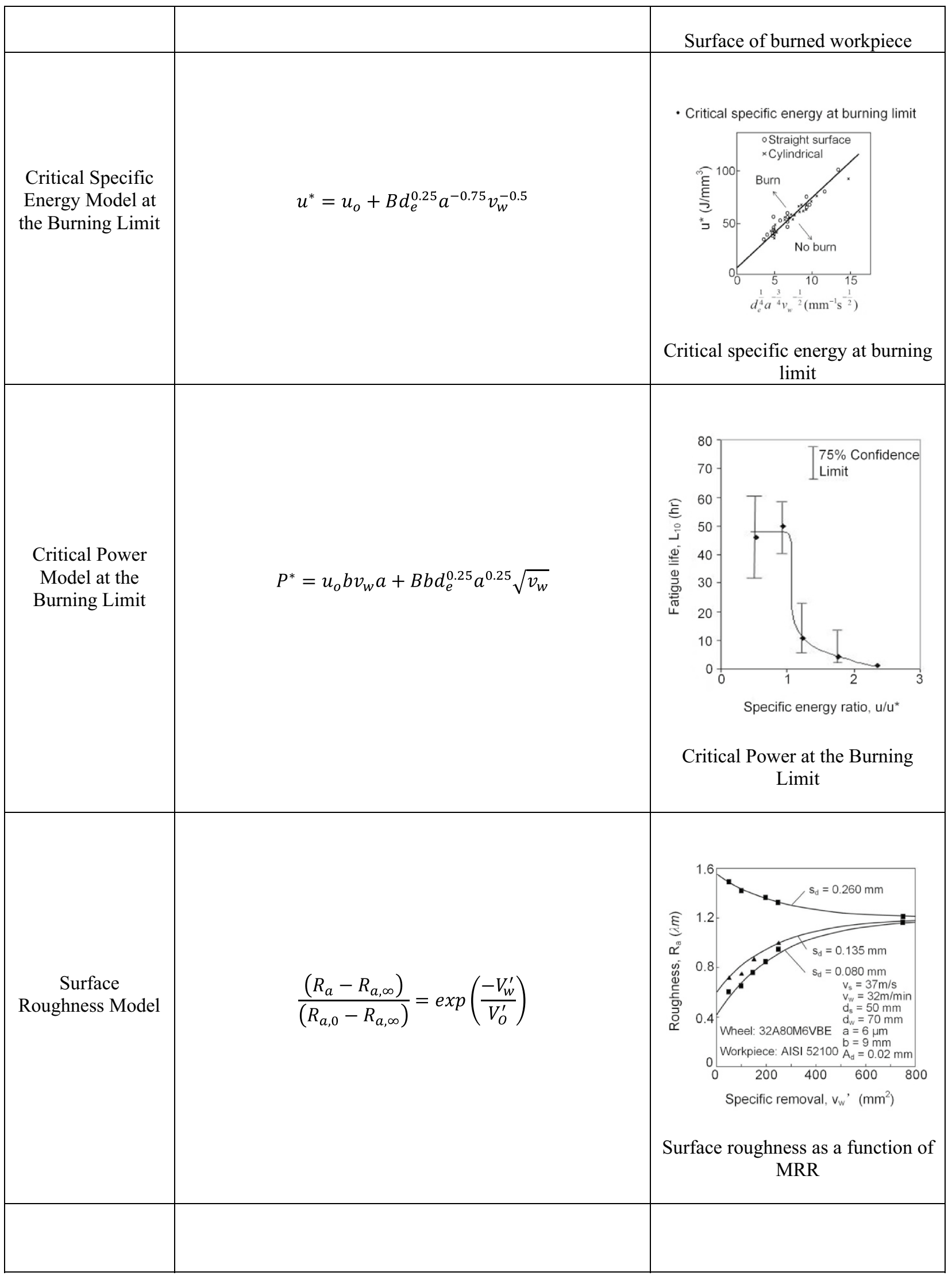


Table 1 (continued)

\begin{tabular}{|c|c|c|}
\hline $\begin{array}{l}\text { Out-of-Roundness } \\
\text { Model }\end{array}$ & $r=r_{m}+r_{o} a$ & 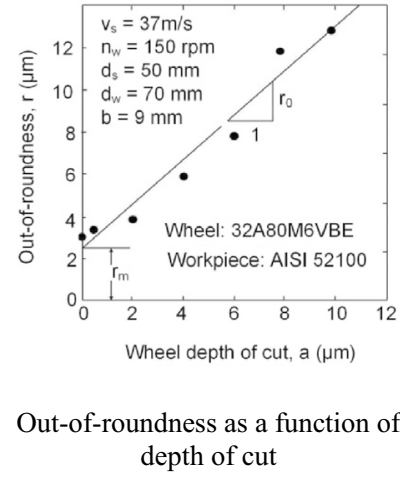 \\
\hline $\begin{array}{l}\text { Continuity } \\
\text { Equation Model } \\
\text { for Grinding } \\
\text { Infeed }\end{array}$ & $u(t)-v(t)-w(t)=\frac{d \delta}{d t}$ & Infeed grinding cycle \\
\hline $\begin{array}{l}\text { Deflection Model } \\
\text { for Grinding } \\
\text { Infeed }\end{array}$ & $F_{n}=k_{g} \delta:$ where $k_{g}^{-1}=k_{s}^{-1}+k_{w}^{-1}+k_{a}^{-1}$ & Deflection of grinding wheel and \\
\hline $\begin{array}{l}\text { Infeed Rate, } \\
\text { Depth of Cut, } \\
\text { Wheel Wear, and } \\
\text { Grinding Ratio for } \\
\text { Grinding Infeed }\end{array}$ & $\begin{array}{l}\text { Infeed Rate and Depth of Cut: } \\
\qquad v(t)=a n_{w} \\
\text { Wheel Wear: }\end{array}$ & \\
\hline & $\begin{array}{l}\qquad w(t)=\frac{v(t) d_{w}}{G d_{s}} \\
\text { G-ratio: } \\
\qquad G=g_{o}\left(\frac{Q_{w}^{\prime}}{v_{s}}\right)^{-g}\end{array}$ & Centerless grinding machine with \\
\hline
\end{tabular}


equivalent diameter, $d_{\mathrm{e}^{\prime}}$ plowing force, $\mathrm{F}_{\text {plowing, }}$ and the friction coefficient, $\mu$ :

$F_{t}=\frac{u_{c h i p} v_{w} b a}{v_{s}}+\mu p_{c} A_{\text {effective }} b \sqrt{d_{e} a}+F_{\text {tplowing }}$

$F_{n}=\frac{k_{\text {chip }} u_{\text {chip }} v_{w} b a}{v_{s}}+p_{c} A_{\text {effective }} b \sqrt{d_{e} a}+k_{\text {plowing }} F_{\text {tplowing }}$

where $\mathrm{k}_{\text {chip }}$ is a constant ratio associated with the chip formation and is $\sim 2$, and $k_{\text {plowing }}$ is a constant ratio associated with plowing of the surface material and is $\sim 2$. The plowing force described in these equations is that caused by the path of the abrasive grit plowing into material at a critical removal rate of $\sim 1 \mathrm{~N} / \mathrm{mm}$ depth of cut. The associated normal and tangential plowing forces are:

$F_{\text {tplowing }}=F_{\text {plowing }}\left(v_{w} a\right)$

$F_{\text {nplowing }}=k_{\text {plowing }} F_{\text {plowing }}\left(v_{w} a\right)$

The associated normal and tangential sliding forces are:

$F_{\text {nsliding }}=p_{c} A_{\text {effective }} b \sqrt{d_{c} a}$

$F_{\text {tsliding }}=\mu F_{\text {nsliding }}$

For the chip formation force models, both normal and tangential components require the chip formation specific energy, which is $13.8 \mathrm{~J} / \mathrm{mm}^{3}$ for iron-carbon alloy materials, and $\mathrm{k}_{\text {chip }} \sim 2$ :

$F_{\text {tchip }}=\frac{u_{c h i p} v_{w} b a}{v_{s}}$

$F_{\text {nchip }}=\frac{k_{\text {chip }} u_{\text {chip }} v_{w} b a}{v_{s}}$

The contact stress is a function of the curvature difference between abrasive grit and cut workpiece, i.e. the cutting path radius, $R$, affects the contact stress by the following relationship:

$p_{c}=c_{c} \Delta$

where $p_{c}$ is the contact stress, $c_{c}$ is constant and $\Delta$ is the curvature difference:

$\Delta=\frac{2}{d_{s}}-\frac{1}{R} \approx \frac{4 v_{w}}{d_{e} v_{s}}$ where $d_{s}$ is the wheel diameter, $R$ is the cutting path radius, and $d_{e}$ is the effective diameter. The magnitude of grinding forces and the subsequent stresses generated on the surface of the workpiece material is dependent on the wear flat area of each active abrasive grit and the effective wear flat area model is:

$A_{\text {effective }}=A_{O, \text { effective }}+A_{\text {dull }}-A_{\text {sharp }}$

where $A_{o, \text { effective }}$ is the initial effective wear flat area, $A_{d u l l}$ is the dulling of the grit due to wear by attrition, and $A_{\text {sharp }}$ is the self-sharpening effect caused by attrition of the grit. The initial wear flat area an empirical measure of wear flat area and is dependent on the dressing lead and the depth of cut during the dressing operation:

$A_{O, \text { effective }}=-A_{O} \ln \left(\frac{A_{1} \delta}{f(w)}\right)$

where $A_{\circ}$ and $A_{1}$ are empirical parameters, $f(w)$ is a parameter that depends on the type of lubricating fluid used and the Abrasive grit type, and $\delta$ is the dressing severity parameter:

$\delta=a_{O} s_{d}^{1.75} a_{d}^{0.75}$

where $a_{o}$ is the initial dressing depth, $s_{d}$ is the dressing feed and $a_{d}$ is the dressing depth. After grinding begins the abrasive grit will progressively wear away by attrition and is calculated, thus:

$A_{\text {dull }}=k_{l} I_{\text {sliding }}$

where $k_{1}$ is the wear constant for a specific grinding wheel and workpiece and $I_{\text {sliding }}$ is the accumulated sliding distance. When considering the sliding length along the path of grinding the wear flat area is a function of the wheelworkpiece contact length:

$I_{\text {sliding }}=\int_{0}^{t} \frac{v_{s} I_{c}}{\pi d_{s}} d t$

where $I_{c}$ is the wheel-work contact length, $I_{c}=\left(a \cdot d_{e}\right)^{0.5}$ and $d_{e}=\left(\left(d_{w} \cdot d_{s}\right) /\left(d_{w} \pm d_{s}\right)\right)$. When the chip begins to be cut by the engagement of an abrasive grit, the specific energy and power models surrounding the grinding process are:

$u=u_{\text {chip }}+u_{\text {sliding }}+u_{\text {plowing }}$

$P=P_{\text {chip }}+P_{\text {sliding }}+P_{\text {plowing }}=F_{t} v_{s}$

where the total specific energy and power is composed of the components of chip formation, sliding and plowing of the workpiece material. The energy and power equations associated with chip formation are: 
$u_{\text {chip }}=\frac{F_{\text {tchip }} v_{s}}{b v_{s} a}$

$P_{\text {chip }}=u_{\text {chip }} v_{w} b a$

Where the chip formation energy $=13.8 \mathrm{~J} / \mathrm{mm}^{3}$ and $\mu \sim 3$. The power associated with plowing and sliding interactions are:

$P_{\text {tplowing }}=F_{\text {tplowing }} v_{s}$

$P_{\text {sliding }}=\mu p_{c} A_{\text {effective }} \sqrt{d_{e} a} v_{s} b$

Total power being, $P=P_{\text {chip }}+P_{\text {sliding }}+P_{\text {plowing, }}$ and subsequently,

$P=u_{\text {chip }}\left(b v_{w} a\right)+\mu p_{c} A_{\text {effective }} b \sqrt{d_{e} a} v_{s}+F_{\text {tplowing }} v_{s}$

In addition to modelling forces, power and energy in grinding, one output that can be considered detrimental to producing a crack-free surface is the rise in temperature. Therefore, much effort has been put into thermal modelling of the grinding process and is very well documented [8]. The maximum temperature can be calculated using the following model:

$\theta_{\text {maximum }}=\frac{1.13 q_{w} \sqrt{\alpha} a^{0.25} d_{e}^{0.25}}{k \sqrt{v_{w}}}$

where $k$ is the thermal conductivity, a is the depth of cut, $v_{w}=$ work speed, $a$ is the thermal diffusivity, $q_{w}$ is the heat flux partitioned to the workpiece and $d_{e}$ is the equivalent diameter. The heat flux to the workpiece is, $q_{w}=\frac{\varepsilon P}{b l_{c}}$, where $\varepsilon$ is the heat partitioned to the workpiece along the contact length, $I_{c}=\sqrt{a d_{e}}$ with an the effective diameter, $d_{e}=\frac{d_{w} d_{s}}{d_{w} \pm d_{s}}$. For alumina grinding wheels, the maximum temperature is:

$\theta_{\text {maximum }}=\frac{1.13 \sqrt{\alpha} a^{0.75} \sqrt{v_{w}}\left(u-0.45 u_{\text {chip }}\right)}{k d_{e}^{0.25}}$

The model used for predicting workpiece burn at a particular critical temperature $\theta^{*}$ where a phase transformation occurs in the material is provided by:

$\theta^{*}=\frac{1.13 \sqrt{\alpha} a^{0.75} \sqrt{v_{w}}\left(u-0.45 u_{\text {chip }}\right)}{k d_{e}^{0.25}}$

The critical specific energy at the burn temperature is,

$u^{*}=u_{o}+B d_{e}^{0.25} a^{-0.75} v_{w}^{-0.5}$ where $\mathrm{u}_{\mathrm{o}}=0.45 . \mathrm{u}_{\text {chip }}$ and $B=\frac{k \theta^{*}}{1.13 \sqrt{\alpha}}$. For the case of steel, $B=7.2 \mathrm{~J} / \mathrm{mm}^{2} \mathrm{~s}^{1 / 2}$ and $\mathrm{u}_{\mathrm{o}} \sim 6.17 \mathrm{~J} / \mathrm{mm}^{3}$. The critical power at the burning limit is:

$P^{*}=u_{o} b v_{w} a+B b d_{e}^{0.25} a^{0.25} \sqrt{v_{w}}$

It should be noted that there is no workpiece burn when $\mathrm{P}<\mathrm{P}^{*}$. The model used to predict the generated surface roughness is:

$\frac{\left(R_{a}-R_{a, \infty}\right)}{\left(R_{a, 0}-R_{a, \infty}\right)}=\exp \left(\frac{-V_{w}^{\prime}}{V_{O}^{\prime}}\right)$

where $R_{a, \infty}=R_{g}\left(Q_{w}^{\prime}\right)^{\gamma}$ and $R_{a, O}=R_{O} S_{d}^{x} a_{d}^{y}\left(\frac{Q_{w}^{\prime}}{V_{s}}\right)^{\gamma}$. It must be remembered that $V_{w}{ }^{\prime}$ is the accumulated metal removal per unit width, $V_{o}{ }^{\prime}$ is a constant, $R_{o}$ is constant, $Q_{w}{ }^{\prime}$ is the removal rate per unit width $\left(\mathrm{mm}^{2} / \mathrm{s}\right), x, y$ and $\gamma$ are constants, typically: $x=0.75, y=0.5$ and $\gamma=0.33$. The associated out-of-roundness of cylindrically ground components are modelled as a function of the depth of cut. The model equation is:

$r=r_{m}+r_{o} a$

where the out-of-roundness, $r$, is equal to the constant, $r_{m}$ (which is equal to $2.4 \mu \mathrm{m}$ ) plus the wheel depth of cut multiplied by the constant, $r_{o}$, which is approximately equal to 1 . In order to incorporate these models into the manufacturing envelope for minimizing burn, generating the correct surface finish and minimizing out-of-roundness for cylindrical workpieces, grinding systems must be adapted to respond to the operational parameters being monitored. This requires models that control the level of infeed of the grinding wheel to the workpiece material and is usually modelled using a continuity equation, thus:

$u(t)-v(t)-w(t)=\frac{d \delta}{d t}$

where $v(t)=a \cdot n_{w}, w(t)=\left(v(t) \cdot d_{w} / G \cdot d_{s}\right)$, and $F_{n}=k_{s} \cdot \delta$. Here, $\mathrm{a}=$ depth of cut, $\mathrm{n}_{\mathrm{w}}=$ workpiece speed, $\mathrm{d}_{\mathrm{w}}$ is the diameter of the workpiece, $d_{s}$ is the diameter of the grinding wheel, $G$ is the grinding ratio, $F_{n}$ is the normal grinding force, $k_{s}$ is the stiffness of the wheel and $\delta$ is the deflection. The deflection is proportional to the normal force and is a function of the overall grinding system stiffness:

$F_{n}=k_{g} \delta: \quad$ where $k_{g}^{-1}=k_{s}^{-1}+k_{w}^{-1}+k_{a}^{-1}$

The actual infeed and depth of cut is $v(t)=a \cdot n_{w}$, the wheel wear is $w(t)=\left(v(t) \cdot d_{w} / G \cdot d_{s}\right)$, and the grinding ratio (or G-ratio), $\mathrm{G}=\mathrm{g}_{\mathrm{o}}\left(\mathrm{Q}_{\mathrm{w}}{ }^{\prime} / \mathrm{v}_{\mathrm{s}}\right)^{-\mathrm{g}}$.

Such models can now be utilized in real time with the advent of powerful computing techniques. The advantages 
of using such techniques for advanced machining processes include better control of the machining process, optimum cycle time, optimized surface finish, less consumed power and energy during the machining process, the elimination of burning and the generation of compressive residual stresses. The advantages are also environmental normally associated with minimizing the subtraction of workpiece material and the minimal removal, or wear, of the cutting tool.

When considering the abrasive machining process of a specific or known cycle time, measurements are taken during the abrasive machining process are focused on the threshold component of power is normally a function of the initial material removal rate (MRR) while the induced power (that is proportional to increasing MRR) is a cutting component of power (interaction 1.1). Thus,

$P=P_{\text {th }}+P_{c}$

The threshold component $\left(P_{t h}\right)$ is associated with sliding and plowing and the cutting component of power $\left(P_{c}\right)$ is treated as the energy per unit time that is needed for forming chips $[5,6]$. This statement is applicable to processes that re-sharpen during grinding causing the power component of cutting to be relatively constant (Fig. 2).
The total power developed during the process is:

$\mathrm{P}=\mathrm{P}_{\mathrm{th}(\mathrm{t}=0)}+\mathrm{P}_{\mathrm{c}(\mathrm{t}=0)}+\mathrm{x}+\mathrm{y}$

where $\mathrm{x}$ is a time-dependent change in the threshold power at $\mathrm{t}=\mathrm{t}$, and $\mathrm{y}$ is the time-dependent change in the cutting (interaction 1.1) component of power, also at $t=t$. If $x+y=0$, the grinding wheel self-sharpens. If power is variable as shown by the shaded area in Fig. 2 , then the grits are dulling, the bond is eroding away and coolant effects are dominating the process because the coolant clears away the grinding chips and controls chip re-circulations. The level of grinding intensity (or grinding cycle) is a combination of roughing, semi-finishing and finishing for a particular MRR $[7,8]$. There are roughing and finishing components corresponding to MRR levels for a plunge grinding process (Fig. 3). The threshold component of power is independent of chip generation [9]. Threshold effects exist in traditional machining processes and is small compared to the effects of shear.

A power signal is superimposed from the first and the fifth cycles corresponding to the grinding of components $1-5$. For the fifth and final cycle, threshold power and its rate of development has altered (Fig. 3). Advances
Fig. 2 Time-dependent behavior of ultraprecision machining processes: a the projections of power as a function of time to $\operatorname{MRR}\left(\mathrm{Q}_{\mathrm{w}}{ }^{\prime}\right)$ and associated equations. $\mathbf{b} A$ is the threshold power indicating grit sharpness and effects plus the open or closed behavior of the abrasive product, $B$ is the cutting component of power depending on material, MRR and undeformed chip thickness, $x$ is a time-dependent threshold power due to wear flat formation, bond erosion and coolant effects, and $\mathrm{Y}$ is the timedependent frictional power that depends on coolant, filtration effects and the type of material ground. Adapted from drawings provided by Dr. Michael Hitchiner and Dr. Subramanian, Saint-Gobain Abrasives, Worcester, Massachusetts, USA

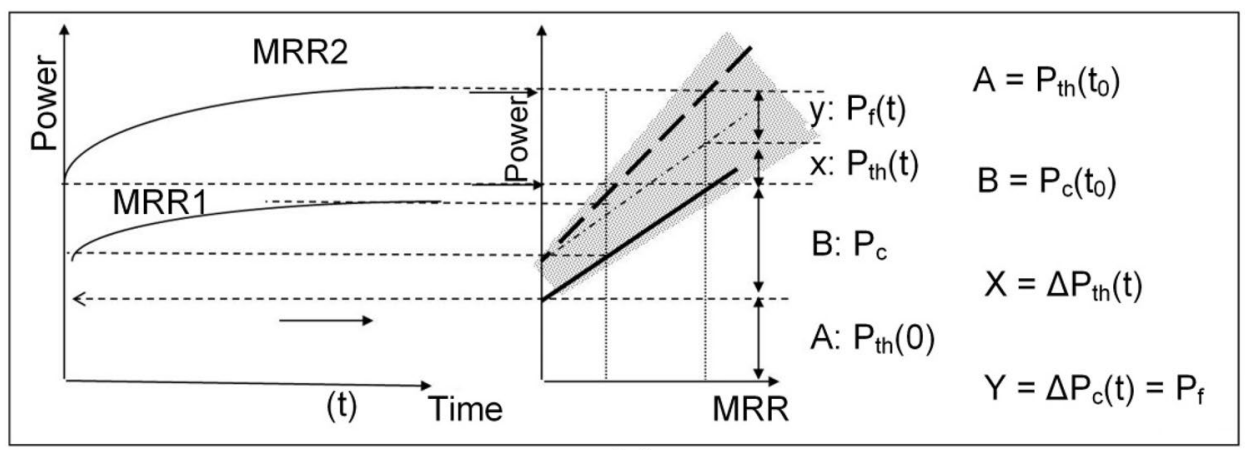

(a)

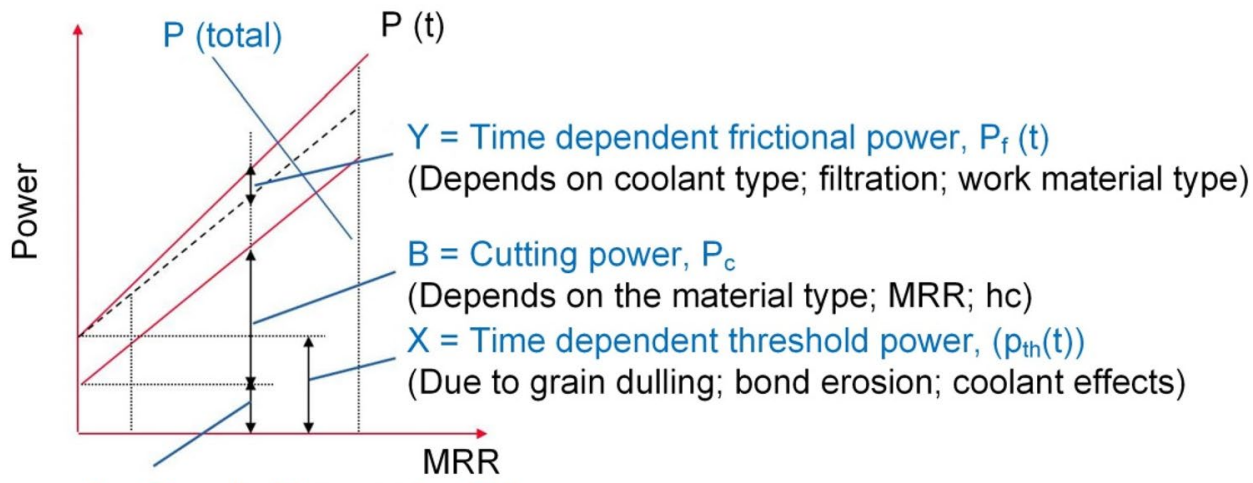

$A=$ Threshold power $\left(p_{\text {th }}(0)\right)$

(Indication of product sharpness: grain type effects (orientation, friability), product construction (open vs. closed coat))

(b) 
Fig. 3 The level of power and components of the cycle: a raw data showing power and displacement as a function of time; $\mathbf{b}$ power cycle as a function of time for one and five ground components superposed to the power versus MRR graph showing associated microscopic interactions for the first and fifth cycle. Adapted from drawings provided by Dr. Michael Hitchiner and Dr. Subramanian, Saint-Gobain Abrasives, Worcester, Massachusetts, USA

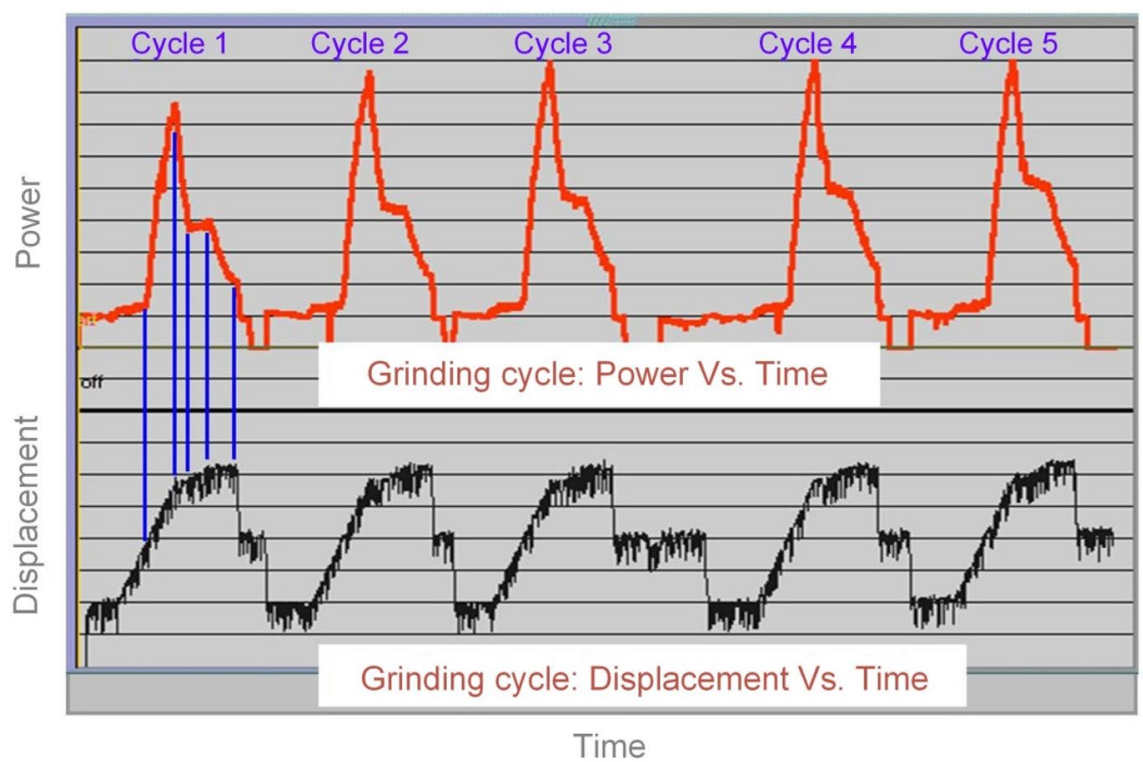

(a)

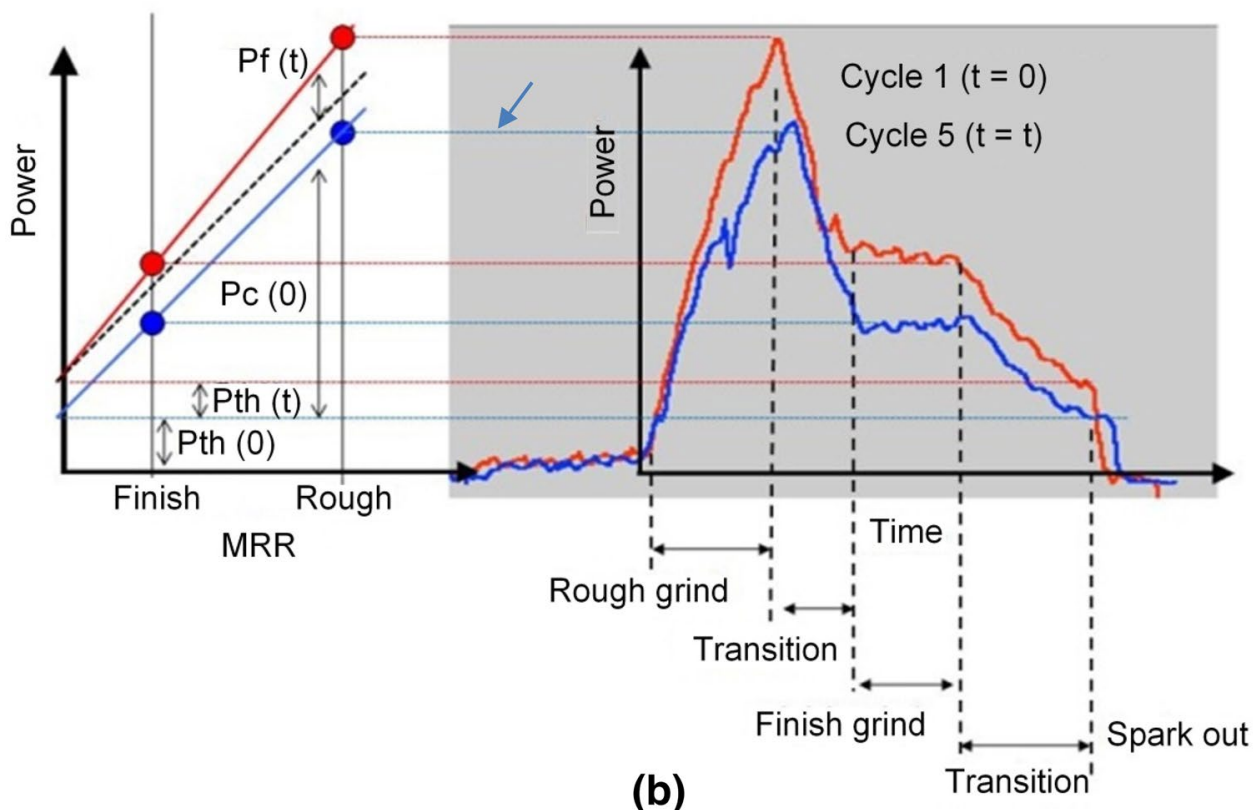

(b)

of chip friction, $P_{f}(t=t)$. The relationship of the parameters, $P_{t h}(t=0), P_{t h}(t=t), P_{c}$ and $P_{f}(t=t)$ and microscopic interactions (The threshold initial effect, $P_{t h}(t=0)$, is due abrasive grit/workpiece sliding (1.2 and 1.3) and is steady (Fig. 4). The variation in $P_{t h}$ with time, $P_{t h}(t=t)$, is caused by the time-dependent nature of grit/workpiece sliding as well as certain bond/workpiece sliding features. If the abrasive grit fractures or wears by attrition, the $P_{t h}(t=t)$ may decrease in value (characteristic of fused abrasive grits). For tougher abrasive grits, then $\mathrm{P}_{t h}(\mathrm{t}=\mathrm{t})$ could increase in value (engineered ceramic abrasive grits). Chip creation power is denoted by $P_{c}[9,10]$. Changes in $P_{f}(t=t)$ caused wer at a specific moment in time, $P_{t h}(t=t)$, power fo chip making, $P_{c^{\prime}}$ and cutting power caused by the effects 
Fig. 4 Frictional interactions decomposed into their components and their power effects. Adapted from drawings provided by Dr. Michael Hitchiner and Dr. Subramanian, Saint-Gobain Abrasives, Worcester, Massachusetts, USA

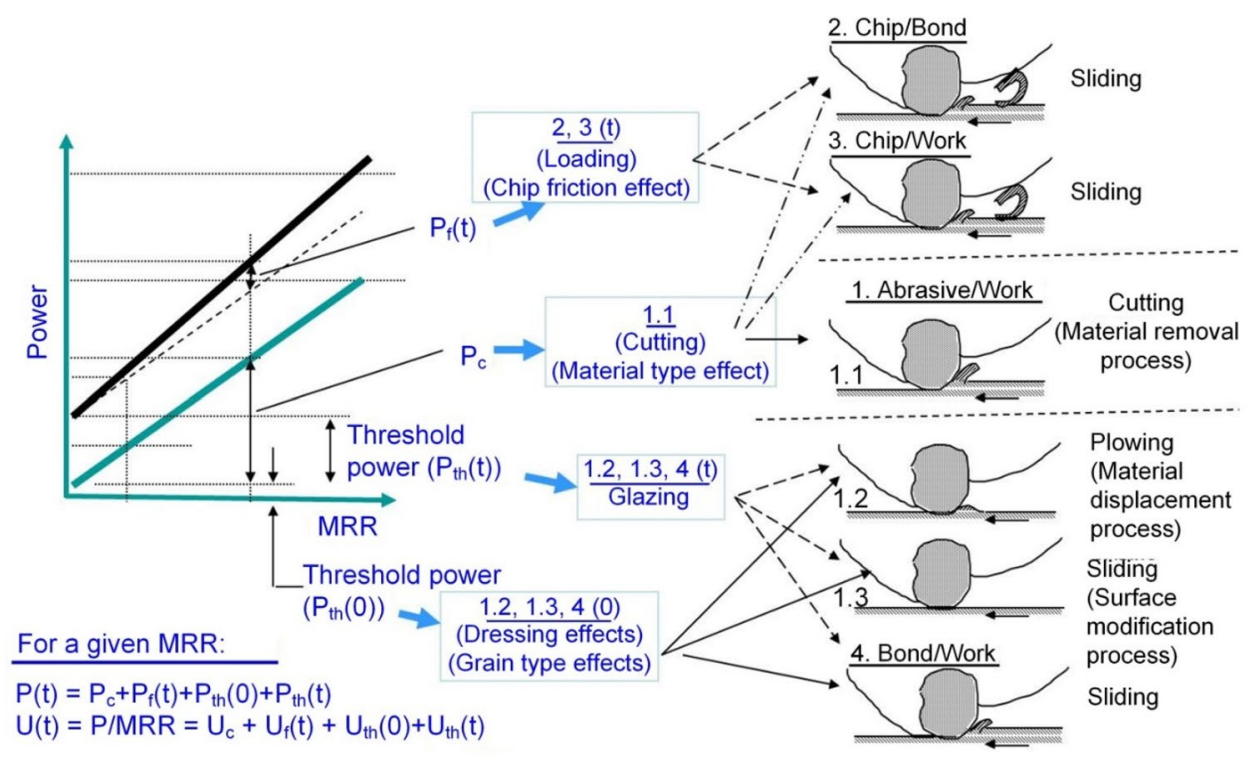

by chip/tool and chip/workpiece friction (interactions 2 and 3) will cause effects that vary with time.

The process of cutting (interaction 1.1), or the single shear plane chip making process, is generally described by Timme, Piispanen and Ernst and Merchant's models for small chip thickness ratios (Fig. 5) [11]. The shear zone models for large chip thickness ratios are described by Zorev and Briks are shown in Fig. 6.
It is noted from physical observations of machine surfaces that cut surfaces do not always conform to the path and contours formed by the cutting tool and are modified by irregularities that extend in the direction perpendicular to the directions of flowing chips. This makes it difficult to assess whether the single plane shearing model or the shearing zone model is applicable to any one machining operation. Therefore, the chip thickness ratio $\left(r_{c}=t_{1} /\right.$

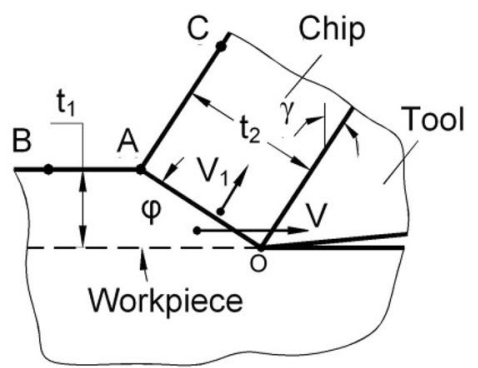

(a)

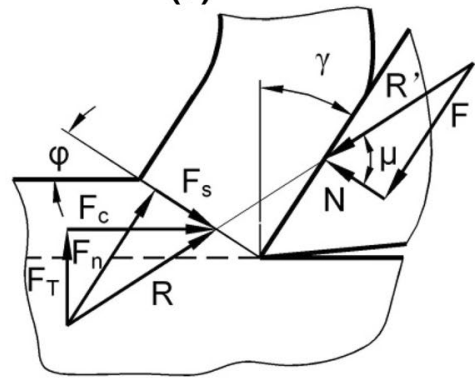

(c)

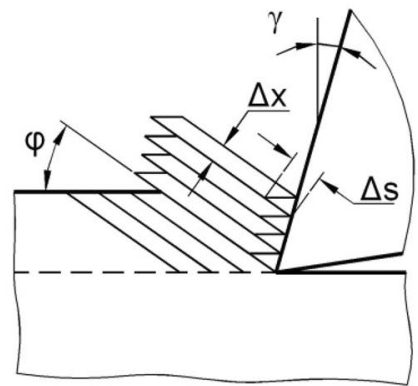

(b)

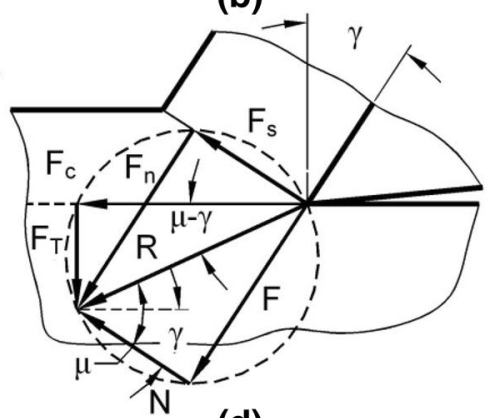

(d)

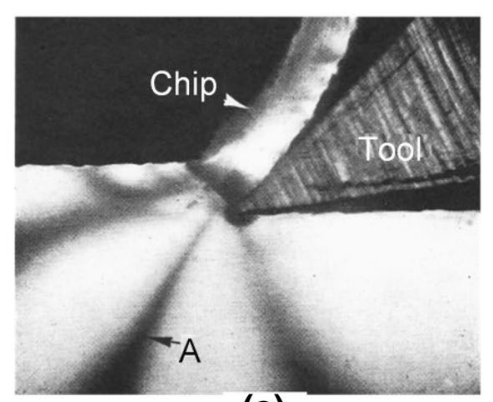

(e)
Fig. 5 Single shear plane models: a schematic showing the simplified single shear plane model developed by Timme; b Piispanen's model; c Ernst and Merchant's free body diagram for the chip; $\mathbf{d}$ Ernst and Merchant's corrected circle of forces and e photoelastic model showing a primary shear plane when cutting with a small chip thickness ratio [11]. Adapted from drawings provided by Prof. Viktor Astakhov, Michigan State University, USA 
Fig. 6 Single shear zone models: a Zorev's qualitative model; b Zorev's simplified model; c Briks' model; and d photoelastic model showing lines of constant shear within a shear zone when cutting with a large chip thickness ratio [11]. Adapted from drawings provided by Prof. Viktor Astakhov, Michigan State University, USA

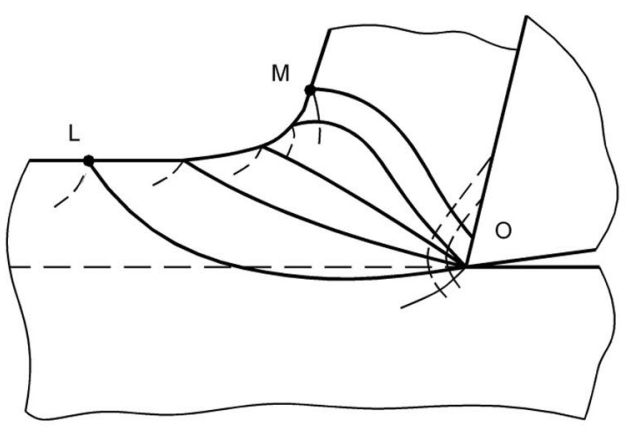

(a)

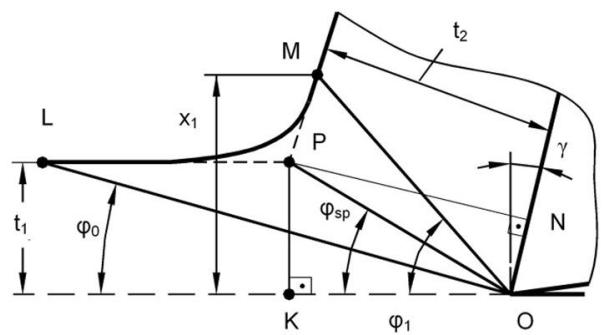

(b)

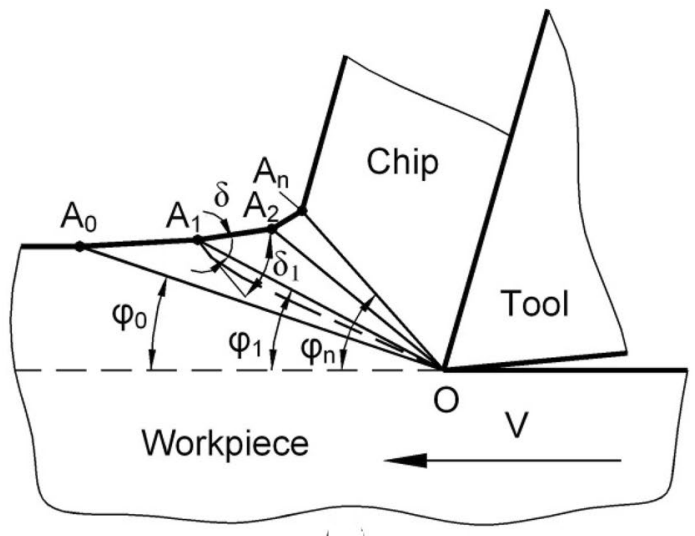

(c)

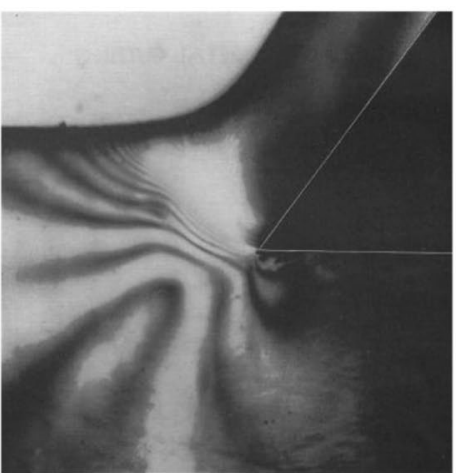

(d) $t_{2}$ ) must play a part in determining which model to use and when one looks at the images of celluloid being cut in Figs. 5 and 6, it appears that very small chip thickness ratios $\left(r_{c}<1\right)$ generate single shear planes, while larger chip thickness ratios $\left(r_{c}>1\right)$ generate shear zones.

Grinding processes are cutting processes with tribological interactions. When the machining component is magnified during rough grinding processes, chip morphology can be characterized and the chips are identical to chips produced using single-point cutting tools and inserts (Fig. 7).

For interaction 1.1, Ernst and Merchant's model provides the force ratio to be $\mathrm{Fc} / \mathrm{Fn}>1$. Reference [12] provides experimental data for orthogonal machining processes (Table 2) [12]. Plowing interactions (interaction 1.2) are similar to the hydrostatic stresses built up in a fully plastic shear zone. Therefore, $\mathrm{Ft} / \mathrm{Fn} \sim 1$ for interaction 1.2. Sliding interactions (interaction 1.3) between two bodies of variable hardness produce tangential forces, $F_{t}$, that are proportional to the shear yield stress and the normal force, $F_{n}$ is in proportion to the hardness of the soft body [13]. The force ratio, $F_{t} / F_{n} \sim 1 / 6$, for interaction 1.3, is dominated by the real area of contact. Malkin [14] generated grinding data between abrasive grits and workpiece materials in terms of the real area of contact and is shown in Fig. 8 and Table 3.

From the data given (Table 3), the force ratio changes rapidly for all materials tested once the real area of contact decreases to approximately $2 \%$ to $8 \%$ indicating that there is a reduction in tangential force to $\sim 1 / 6$ because the type of interaction has changed from cutting and plowing to sliding. To prevent these sliding interactions from increasing the surface temperature of the workpiece, lubricating coolants are usually used to prevent the rapid rise in temperature and the subsequent surface damage being inflicted upon the surface of the workpiece. Under these conditions, the coefficient of sliding friction, $\mu$, is usually between 0.3 and 0.5 [15-18]. Hence, the process of grinding becomes a delicate control of the force vectors detailed in Figs. 2 and 4. The grinding cycle seeks to control those forces and depending on the type or types of interaction(s), the power components of $P_{t h}(t=0), P_{t h}(t=t), P_{c}$ and $P_{f}(t=t)$ increase or decrease based on the grinding process. The size of the power components can also be modulated depending on the type of abrasive grit (mechanical and thermal properties) and the in-process change of shape and the tribological characteristics of the abrasive grits and the bonding system in which they are held. The application of the 


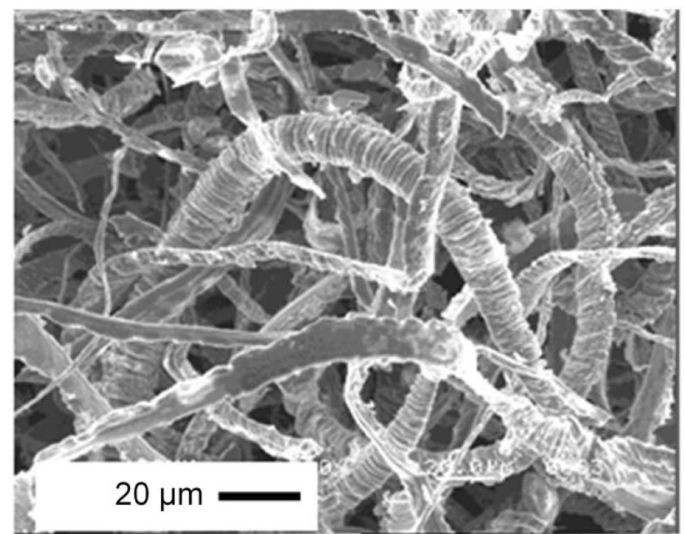

(a)

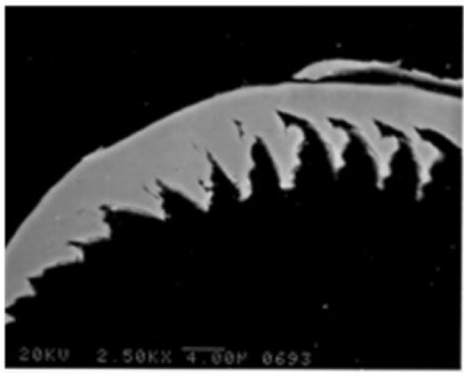

(c)

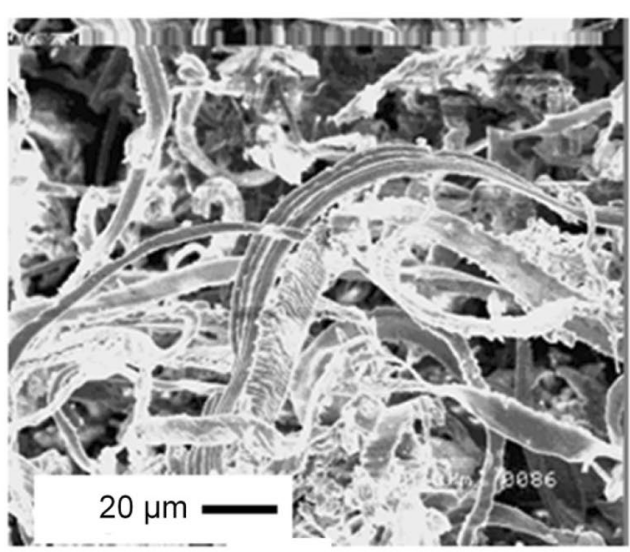

(b)

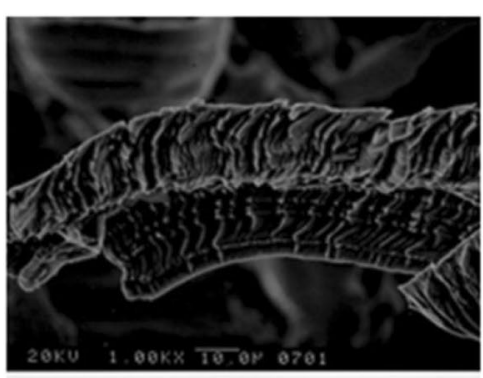

(d)

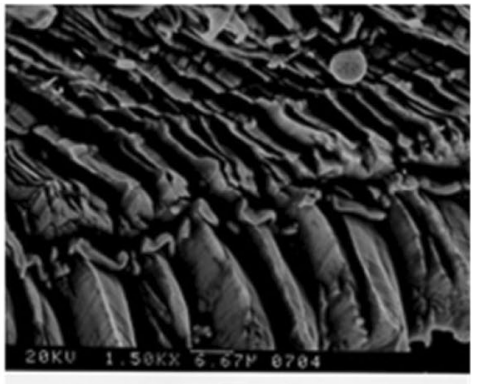

(e)
Fig. 7 Chip formation by cutting during grinding (sliding interaction 1.1): a 1018 low carbon steel; b stainless steel; c cross sectional area of cut chip; and ( $d$ and e) lamellar structure of grinding chips.

Table 2 Force components, $F_{c}$ and $F_{n}$ and the corresponding force ratio for an orthogonal machining experiment [12]

\begin{tabular}{llll}
\hline Time $(\mathrm{min})$ & $\begin{array}{l}\text { Cutting force } \\
\text { Fc (N) }\end{array}$ & $\begin{array}{l}\text { Thurst force Fn } \\
(\mathrm{N})\end{array}$ & $\begin{array}{l}\text { Force } \\
\text { ratio Fc/ } \\
\text { Fn }\end{array}$ \\
\hline 6 & 996 & 476 & 2.1 \\
12 & 955 & 416 & 2.3 \\
18 & 918 & 420 & 2.2 \\
28 & 910 & 386 & 2.4 \\
41 & 881 & 356 & 2.5 \\
54 & 856 & 361 & 2.4 \\
60 & 885 & 414 & 2.1 \\
\hline
\end{tabular}

principle interactions are explained in the next section in the form of industrial case studies.

\subsection{Case studies}

A number of studies have been conducted by Subramanian et alia [1] based on the development of abrasive
Micrographs provided by Dr. Michael Hitchiner, Saint-Gobain Abrasives, Worcester, Massachusetts, USA

products by Saint-Gobain Corporation have been developed and used as training aids for students of grinding science.

\subsubsection{Abrasive grits}

Experiments were conducted to see if dressing affects two types of abrasive grits grinding bearing steel including brown aluminum oxide (friability 35.6) and white aluminum oxide (friability 56.6) [19]. Grinding wheels dressed between grinding cycles and continued to grind steel. The data generated is shown in Fig. 9 and the power as a function of metal removal rate (MRR) is shown in Fig. 10. The parameters derived from the experimental data are shown in Table 4.

The threshold effects for grinding bearing steel with white aluminum oxide is $\sim 0$. The cutting component of power, $\mathrm{P}_{\mathrm{C}^{\prime}}$ and its specific cutting energy ( $\mathrm{SCE}$, where $\mathrm{SCE}=\mathrm{P}_{\mathrm{C}} / \mathrm{MRR}$ ) is similar in magnitude. However, brown aluminum oxide has a lower SCE after dressing meaning that a tough abrasive grit is better at cutting immediately after the dressing process. Also, chip friction interactions (interactions 2 and 3 ) are low at an SCE value of 


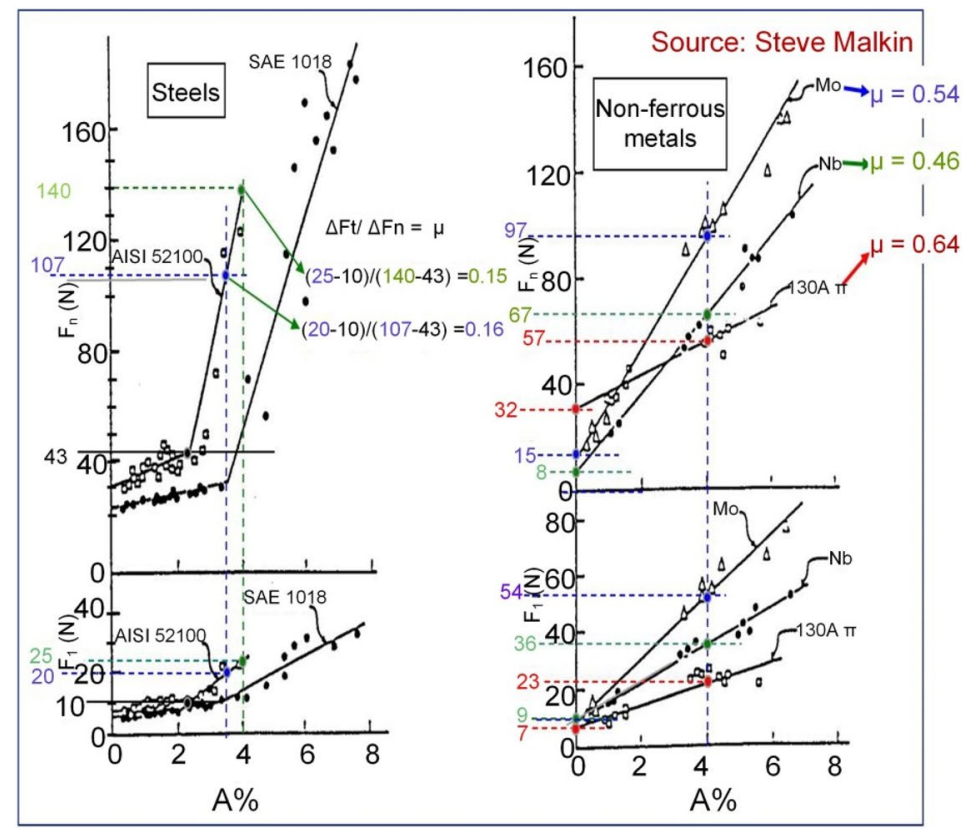

(a) (b)
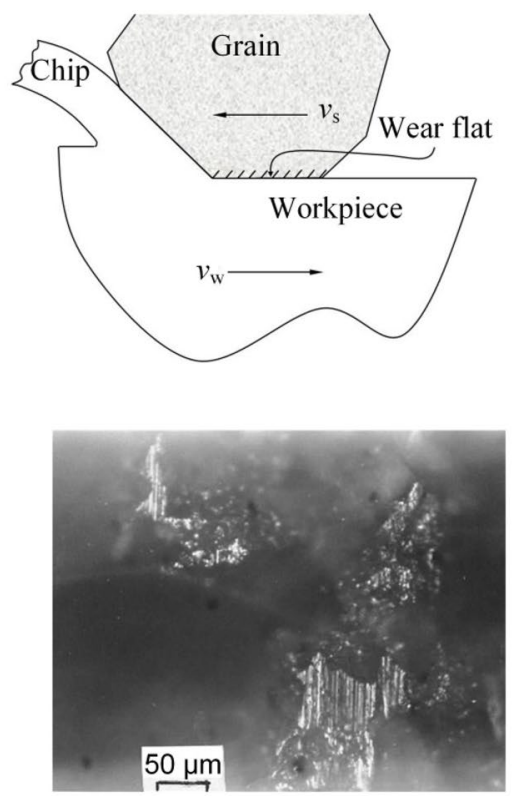

(c)
Fig. 8 Grinding force components for surface plunge grinding of: a two steels (AISI 1018 and 52100); b three non-ferrous metals (molybdenum, niobium and $130 \mathrm{~A}$ titanium) all ground with vitrified grinding wheels (32A46); and c schematic diagram show-

Table 3 Grinding forces and ratios (experimental data from Fig. 9) [14]. Adapted from data provided by Prof. Steve Malkin, University of Massachusetts, USA

\begin{tabular}{lccc}
\hline Material & $\Delta \mathrm{Ft}(\mathrm{N})$ & $\Delta \mathrm{Fn}(\mathrm{N})$ & $\mathrm{Ft} / \mathrm{Fn}$ \\
\hline 1018 Steel & 5 & 12 & 0.42 \\
52100 Steel & 3 & 12 & 0.25 \\
1018 Steel* & 22 & 130 & 0.16 \\
52100 Steel* & 13 & 94 & 0.15 \\
Molybdenum $_{\text {Niobium }}$ & 43 & 85 & 0.54 \\
Titanium & 28 & 60 & 0.46 \\
\hline
\end{tabular}

*Forces after the change in slope

$100 \mathrm{~J} / \mathrm{mm}^{3}$ and that the amount of power above that threshold point are effects caused by friction between chip and abrasive grit.

\subsubsection{Coolant}

Experiments were conducted to see if the type of coolant used in precision grinding reduces sliding friction effects. A nickel-based aerospace alloy ground using neat oil and water-soluble oil was used in the experiments [16]. The resulting grinding force charts as a function of MRR were ing wear flat and micrograph of wear flat area on abrasive grits. Grinding conditions: $V s=30 \mathrm{~m} / \mathrm{s}$, ds $=200 \mathrm{~mm}, \mathrm{Vw}=4.6 \mathrm{~m} / \mathrm{min}$, $\mathrm{a}=25 \mathrm{~mm}, \mathrm{~b}=6.4 \mathrm{~mm}[8,14]$. Adapted from drawings provided by Prof. Steve Malkin, University of Massachusetts, USA

constructed to develop the understanding of the force components during grinding.

It was noted that as chip formation elements, CBN grits do not change their morphology radically as a function of time. However, chip friction effects dominate but are minimized when neat oil is used as the cooling medium, implying that neat oil provides a greater lubricating effect than using water-soluble oils [16]. It is noted that coolant effects on the degradation of abrasive grit and bonding system is not well documented in the literature and this is an area that is ripe for research understanding especially when considering degradation of abrasive grits and bonding systems due to thermal effects.

\subsubsection{Dressing}

Table 5 shows the effects of dressing D2 die steel with high hardness (60 HRC). Vitrified bonded wheels (A80J5V) are used to understand the use of coarse and fine dressing conditions using a blade dressing tool. The grinding cycle was measured in terms of power and displacement [17]. Figure 11 shows the raw data generated using the power meter and the LVDT that measures displacement [18]. The Power as a function of MRR was developed and the derived parameters of $P_{t h}$ and SCE are shown in Fig. 12 and Table 6. Hardened tool steels are typically difficult to cut, so it is relatively easy visualize the threshold power that are 
Fig. 9 Power as a function of grinding time for one grinding cycle: a prior to dressing with diamond and $\mathbf{b}$ post dressing with diamond [1]. Courtesy of Dr. Subramanian, STIMS Institute

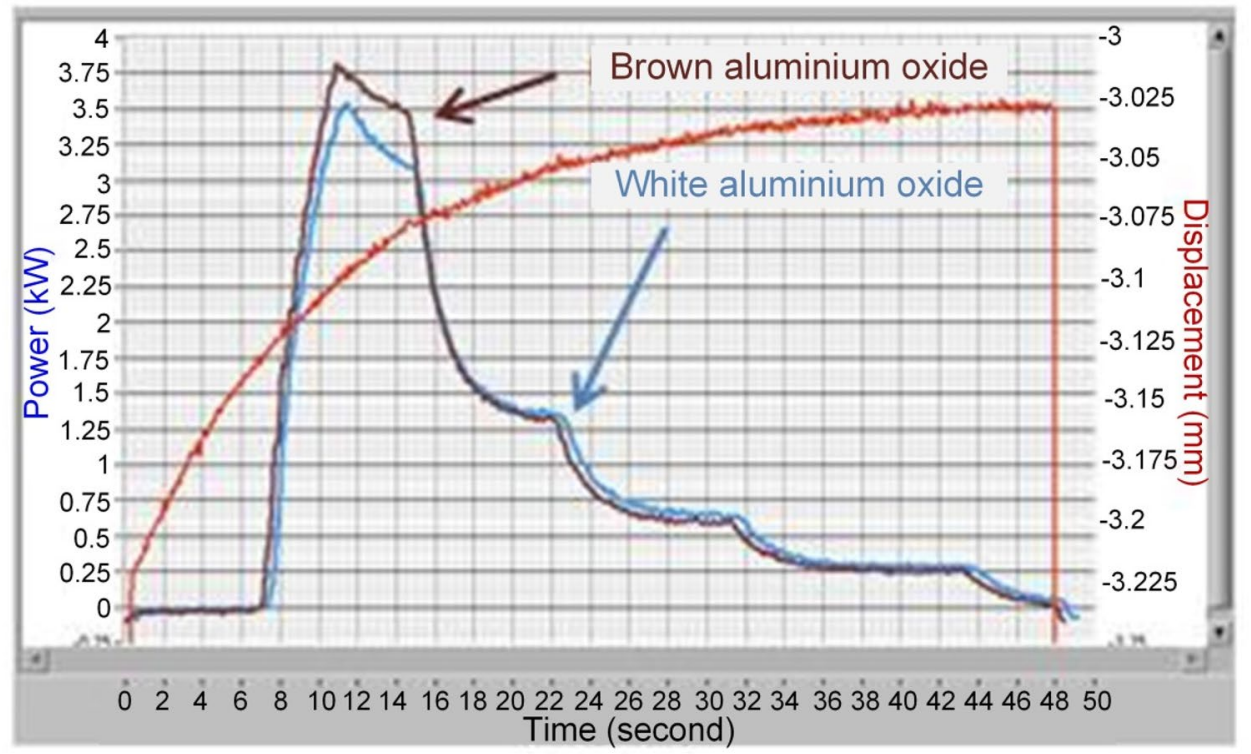

(a)

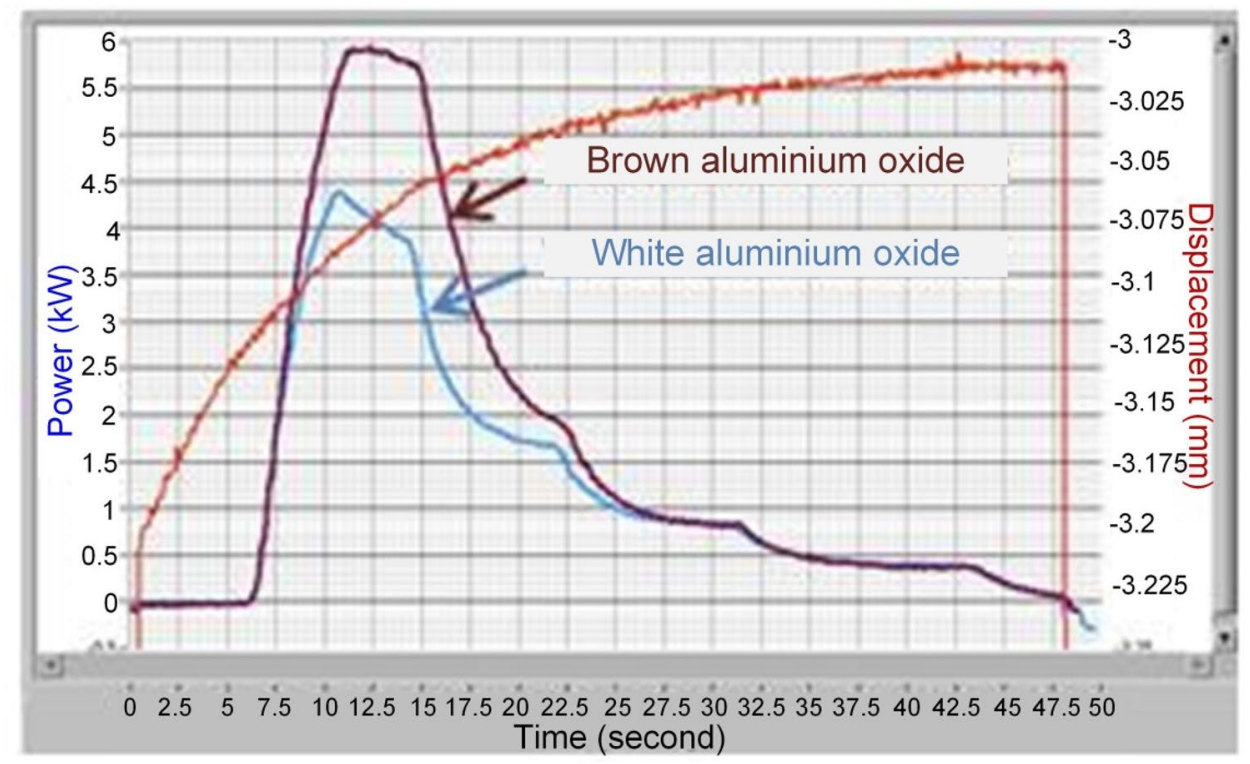

(b)

(a)

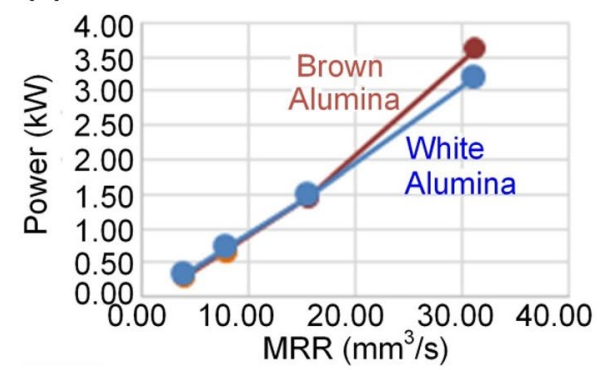

(b) $\quad P$ vs MRR after dressing

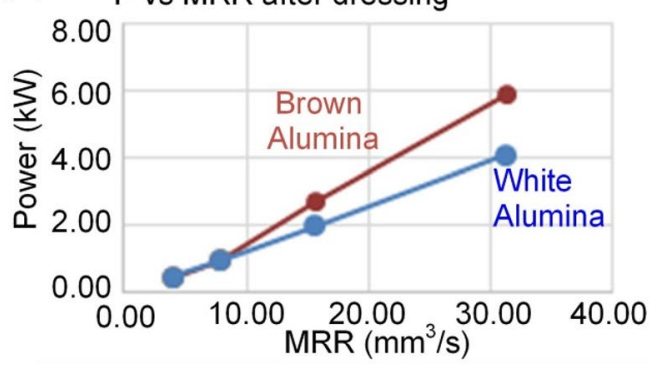


Table 4 Threshold power, $P_{\text {th }}$, and the specific cutting energy (SCE) for white and brown fused alumina grits [1]. Courtesy of Dr. Subramanian, STIMS Institute

\begin{tabular}{llllll}
\hline Abrasive type & \multicolumn{2}{l}{ Before dressing } & & \multicolumn{2}{l}{ After dressing } \\
\cline { 2 - 3 } \cline { 5 - 6 } & $\mathrm{P}_{\mathrm{th}}(\mathrm{kW})$ & $\mathrm{SCE}\left(\mathrm{J} / \mathrm{mm}^{3}\right)$ & & $\mathrm{P}_{\text {th }}(\mathrm{kW})$ & $\mathrm{SCE}\left(\mathrm{J} / \mathrm{mm}^{3}\right)$ \\
\hline Brown aluminum oxide (tough) & 0 & 110 & 0 & 181 \\
White aluminum oxide (friable) & 0 & 100 & 0 & 129 \\
\hline
\end{tabular}

Table 5 Coarse and fine dressing parameters for alumina grinding wheels [17, 18]. Data adapted courtesy of Dr. Subramanian, STIMS Institute

\begin{tabular}{lll}
\hline Cycle & Stock removed (diameter) $(\mathrm{mm})$ & MRR $\left(\mathrm{mm}^{3} / \mathrm{s}\right)$ \\
\hline Grinding cycle & & \\
Rough & $0.80 \mathrm{~mm}$ at $0.66 \mathrm{~mm} / \mathrm{min}$ & 40 \\
Semi-finish & $0.15 \mathrm{~mm}$ at $0.33 \mathrm{~mm} / \mathrm{min}$ & 20 \\
Finish & $0.05 \mathrm{~mm}$ at $0.16 \mathrm{~mm} / \mathrm{min}$ & 10 \\
Spark-out & $15 \mathrm{revolutions}$ & \\
Wheel speed & $45 \mathrm{~m} / \mathrm{s}$ & \\
Work speed & $26 \mathrm{~m} / \mathrm{min}$ & Dressing overlap ratio \\
\hline Case & Infeed $(\mu \mathrm{s})$ & 12 \\
\hline Dressing cycle details & & 6 \\
Fine dressing & 0.015 & 2 \\
Coarse dressing & 0.040 & No. of cycles \\
Dresser spec. & Blade tool & 2 \\
\hline
\end{tabular}

Fig. 11 Grinding signal obtained after coarse and fine dressing $[17,18]$. Figure adapted courtesy of Dr. Subramanian, STIMS Institute

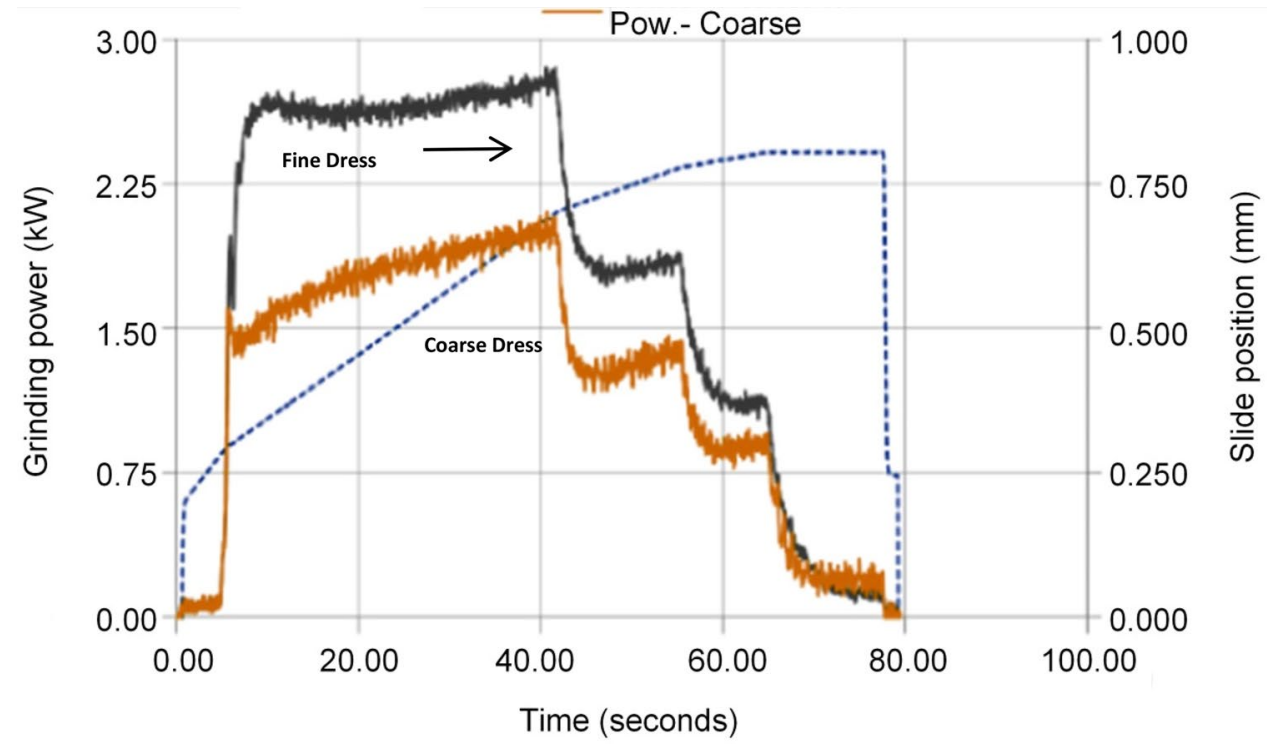

responsible for plowing and sliding interactions (1.2 and 1.3) between abrasive grits and the workpiece material.

Alumina grits readily fracture when grinding and dressing, so the constant value of $P_{\text {th }}$ for coarse dressing and for fine dressing tends to indicate small changes in grit morphology. Coarse dressing tends to open up spaces in the wheel and allows the grits to cut with low power, Pc, and SCE tends to show that this is the case for coarse dressing, suggest that the difference in
SCE of $\sim 24 \mathrm{~J} / \mathrm{mm}^{3}$ is an effect of increased chip friction (interactions 2 and 3), which indicates that less cutting is taking place and that the surface roughness is better than dressing with coarse dressing conditions as shown in Table 5.

The effects of dressing on the degradation of abrasive grit and bonding system is also not well documented in the literature and this is also an area of research that is needed to understand the degradation of abrasive grits 
Fig. 12 Power as a function of MRR and the derived values of $P_{\text {th }}$ and SCE $[17,18]$. Figure adapted courtesy of Dr. Subramanian, STIMS Institute
Power vs MRR

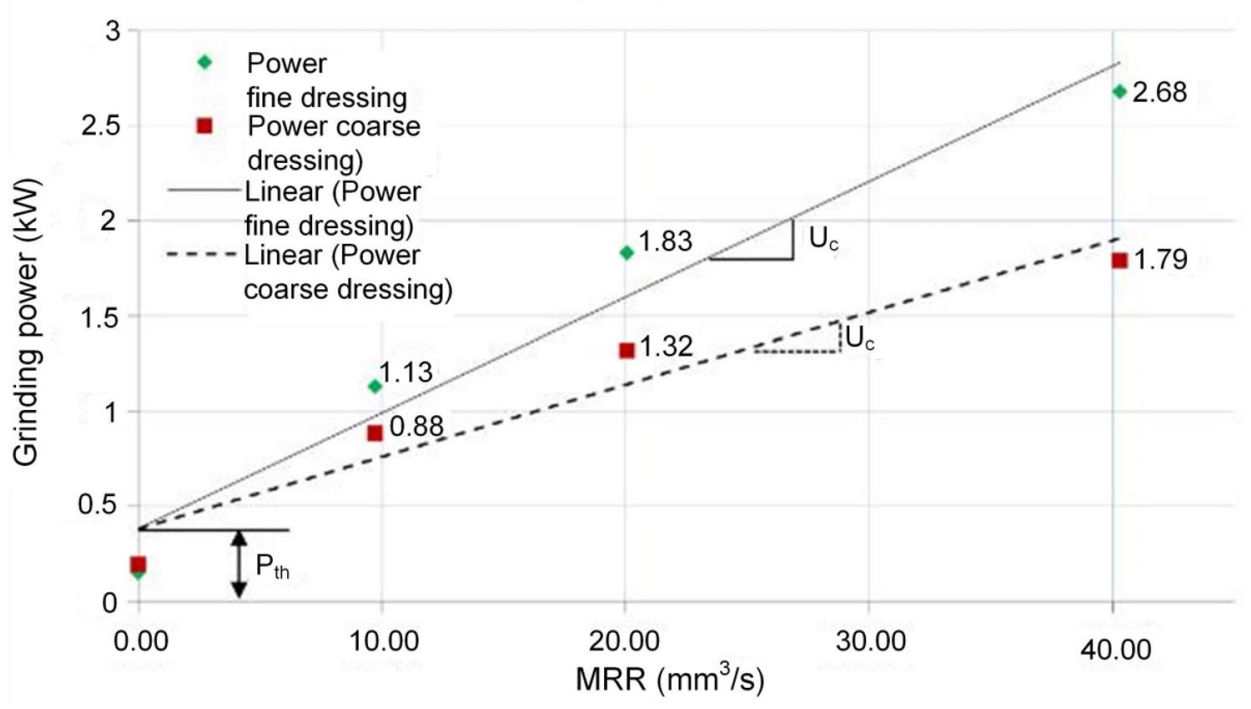

Table 6 Grinding parameters for coarse and fine dressing regimes $[17,18]$. Data adapted courtesy of Dr. Subramanian, STIMS Institute

\begin{tabular}{lll}
\hline Parameter & \multicolumn{2}{l}{ Dressing regime } \\
\cline { 2 - 3 } & Fine & Coarse \\
\hline Specific cutting energy $\left(U_{c}\right)\left(\mathrm{J} / \mathrm{mm}^{3}\right)$ & 62 & 38 \\
Threshold power $\left(P_{t h}\right)(\mathrm{W})$ & 370 & 370 \\
Surface roughness $\left(\mathrm{R}_{\mathrm{a}}\right)(\mu \mathrm{m})$ & 0.32 & 0.56 \\
Surface roughness $\left(\mathrm{R}_{\mathrm{z}}\right)(\mu \mathrm{m})$ & 2.30 & 3.50 \\
\hline
\end{tabular}

and bonding systems due to the mechanical effects of dressing.

\section{Materials science in ultraprecision machining processes}

\subsection{Abrasive grits}

The development of abrasive grits focused on the control of threshold effects (interactions $1.2(t=0)$ and 1.3 $(t=0))$ to minimize the resultant $P_{t h}(t=0)$. This may or may not serve its purpose of achieving certain aspects of the grinding cycle, but not all such as cycle time, workpiece burn or surface finish requirements [19, 20]. Abrasive grits were dressed periodically to create sharp edges for cutting in between cycles in order to alternate between cutting (interaction 1.1) and sliding (interactions 1.2, 1.3 and 4) to achieve surface modification effects. Grits were designed to be friable and their ability to splinter easily was used effectively to dress between cycles. This allowed time-dependent variations of interactions 1.2, 1.3 and 4 to be ignored. However, if interaction 1.1 is sustained for longer periods of time, then the time dependency of $1.2(t=t), 1.3(t=t)$ and 4 $(t=t)$ becomes significant. In effect, the sharpening of grits is dependent upon cutting metal rather than rectification by dressing grits that splinter easily. With the reduction in non-productive time for dressing, more cutting takes place and cycle times are reduced. To satisfy this need, abrasive grits need to be 'engineered' by controlling the micro and nanostructure of abrasive grits by coating [21], alloying alumina with zirconia [22], and by doping $[23,24]$. This has led to alumina grits being close in performance to the superabrasive grit known as cubic boron nitride (CBN) [25]. To understand how materials science plays a role in understanding the grinding process, Hahn and Lindsay [26] and Subramanian and Lindsay [27] created a systems approach of understanding how each mechanism of grinding developed by Malkin et alia [28-31] was affected by the design of the abrasive grain. Consequently, there has been an explosion in engineered grit shapes especially by forming to very specific shapes to control and optimize chip size and shape for high stock removal applications [32]. Developments in the understanding of high-speed grinding [33], high efficiency deep grinding [34] and creep feed grinding [35] have also led to the development of new grains and wheels and their associated microstructures [36]. Agglomerated grits with controlled strength, sharpness and permeability to minimize burn and frictional effects in finish grinding applications have been developed in recent years $[36,37]$. The individual frictional interactions between abrasive grits and workpiece materials have been studied by Marinescu et alia [38] and further refined by Subramanian et alia when studying surfaces [39], ceramics materials [40-43] and 
by Lindsay who studied the concept of the manufacturing envelope in grinding [44]. The grinding of complex shapes [45] requires an understanding of tribological interactions that occur in sequence and in parallel [46], and this knowledge has allowed the further advancements in the design of wheel structures [47] that remove large amounts of materials from stock items such as gear blanks and die blocks $[48,49]$. Further analysis of the behavior and performance of abrasive particles in terms of specific grinding applications are described in great detail by Jackson and Hitchiner [36].

\subsection{Engineered abrasive grits [36]}

Engineered abrasive grits are composed of nanoscale features manufactured by the sol- and seeded gel process that includes sintering and agglomeration of the grains. The abrasive grits made micro-fracture and are microdressed, improving grinding ratio and grindability compared to conventional abrasive grits produced by the conventional fusion process.

Higher threshold forces are normally required to create a self-sharpening effect in engineered abrasives. In conventional grits, reducing crystal sizes from the macroscale to the microscale to sizes $<500 \mathrm{~nm}$, the crystalline structure is significantly enhanced [36]. The consolidation of a-alumina with a homogeneous and densified grit structure starts with the manufacture of Boehmite ( $\gamma$-aluminium oxide hydroxide $\gamma-\mathrm{AlO}(\mathrm{OH})$ ). When mixed with water and acid, aluminum hydrate $\left(\mathrm{Al}_{2} \mathrm{O}_{3} \cdot \mathrm{H}_{2} \mathrm{O}\right)$ with a size $\sim 100 \mathrm{~nm}$ is dehydrated, shaped and sintered to form abrasive grits. Two paths have been developed to reduce activation energy and control crystal form and size (Fig. 13a). The first path promotes the creation of a multi-composite structure through the use of appropriate seeding agents, the second path is the production of single a-alumina structure (Fig. 13b-d).

Patents cite the use of $\mathrm{MgO}$ that forms a bi-composite structure of $a$-alumina plus $\mathrm{MgAl}_{2} \mathrm{O}_{4} \sim 25 \%$ by volume when sintered (Fig. 13b). A large number of patents report multi-phase systems using various modifying agents including $\mathrm{ZrO}_{2}, \mathrm{Mn}_{2} \mathrm{O}_{3}, \mathrm{Cr}_{2} \mathrm{O}_{3}, \mathrm{NiO}$ and rare earth oxides. A popular grit containing $\mathrm{MgO}$ together with $\mathrm{Y}_{2} \mathrm{O}_{3}$ and other rare earth oxides such as $\mathrm{La}_{2} \mathrm{O}_{3}$ and $\mathrm{Nd}_{2} \mathrm{O}_{3}$ produces a very hard grit $(\sim 19 \mathrm{GPa})$ with a submicron magnetoplumbite acicular structure of formed from using these particular modifying agents (Fig. 13c). The alternative route to controlling crystallization rates is by seeding the solvent with nano-scale $(<100 \mathrm{~nm})$ $a$-alumina or with other compounds (a-ferric oxide or titanates). Additions of between 1 and $5 \%$ of seeding agents create a heterogeneous nucleant by increasing the number of nucleation sites from $10^{11}$ to $10^{14} / \mathrm{cm}^{3}$, and an average crystal size of $\sim 400 \mathrm{~nm}$ (Fig. 13d). Special bonding systems have been developed to be sintered at $<1000^{\circ} \mathrm{C}$. Sol-gel manufacturing allows the control of abrasive grit shape. Crushing and milling methods produce strong (blocky) or weak (angular) shapes where
Fig. 13 a Sintered aluminum oxide grit made with Boehmite without modifying agent (image size $3 \mu \mathrm{m} \times 3 \mu \mathrm{m}$ ); $\mathbf{b}$ Sintered aluminum oxide grit made with Boehmite and $\mathrm{MgO}$ modifying agent (image size $3 \mu \mathrm{m} \times 3 \mu \mathrm{m}$ ); $\mathbf{c}$ Sintered aluminum oxide grit made with Boehmite and $\mathrm{MgO}, \mathrm{Y}_{2} \mathrm{O}_{3}, \mathrm{La}_{2} \mathrm{O}_{3}$ and $\mathrm{Nd}_{2} \mathrm{O}_{3}$ modifying agents (image size $1.5 \mu \mathrm{m} \times 1.5 \mu \mathrm{m})$; and d Sintered aluminum oxide grit made with Boehmite and seeding agent (image size $1.5 \mu \mathrm{m} \times 1.5 \mu \mathrm{m})$ [36] Courtesy of Dr. Michael Hitchiner of Saint-Gobain Abrasives
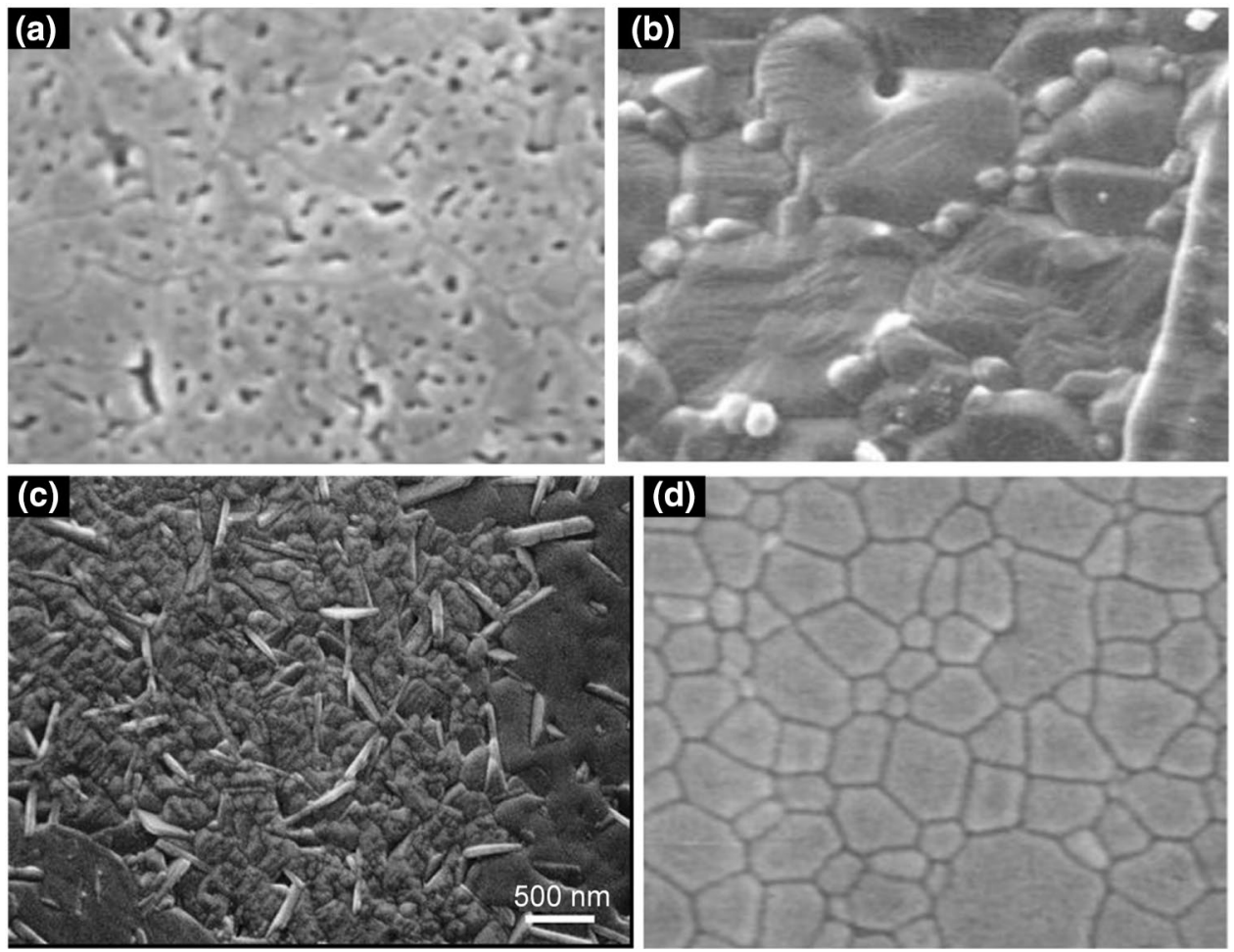
(a)

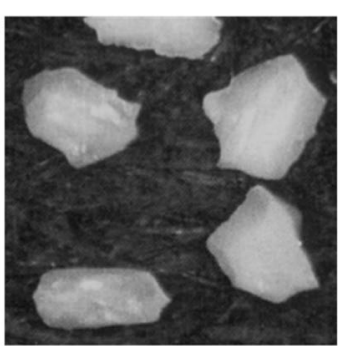

(c)

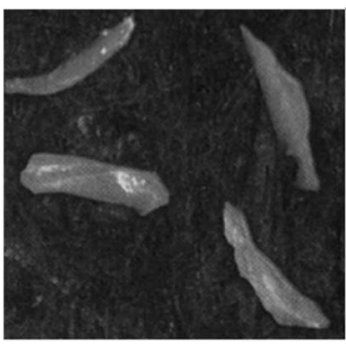

(b)

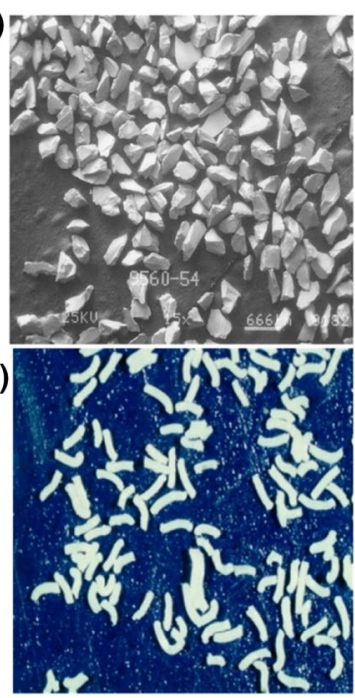

Fig. 14 a Engineered ceramic grits produced by milling; $\mathbf{b}$ friable angular grits produced by crushing; c weak angular grit produced by crushing in the green state; and $\mathbf{d}$ extruded ceramic grits [36] Courtesy Saint-Gobain Abrasives

angularity can be increased by careful processing of soft, dried pre-sintered material (Fig. 14). manufacturing techniques have been developed to extrude grits as rectangular prisms with aspect ratios of $8: 1$ and having the appearance of surfaces that are defect free (Fig. 15).

The latest developments in abrasive grit technology is focused on controlling spinel inclusions at grit boundaries so that it can be micro-dressed with dress depths in the 5-15 $\mu \mathrm{m}$ range to generates sharp and durable cutting edges (Fig. 16).

As with all new shapes of abrasive grits, although packing density can be controlled to a large extent by shape, the threshold forces required to sharpen the edges of these grits is much higher than for fused abrasive grits. One way to control this aspect is to produce a porous grit by agglomeration of smaller grits using an appropriate bonding agent. Agglomerated grits require lower threshold forces to fracture the agglomerate and this leads to coarse micro-fracturing compared to engineered ceramic grits. However, no wear flats are generated thus producing a continuous form of cutting (interaction 1.1) and the elimination of plowing and sliding (interactions 1.2 and 1.3) due to the non-formation of wear flats. A stronger bond is usually used in these types of products in order
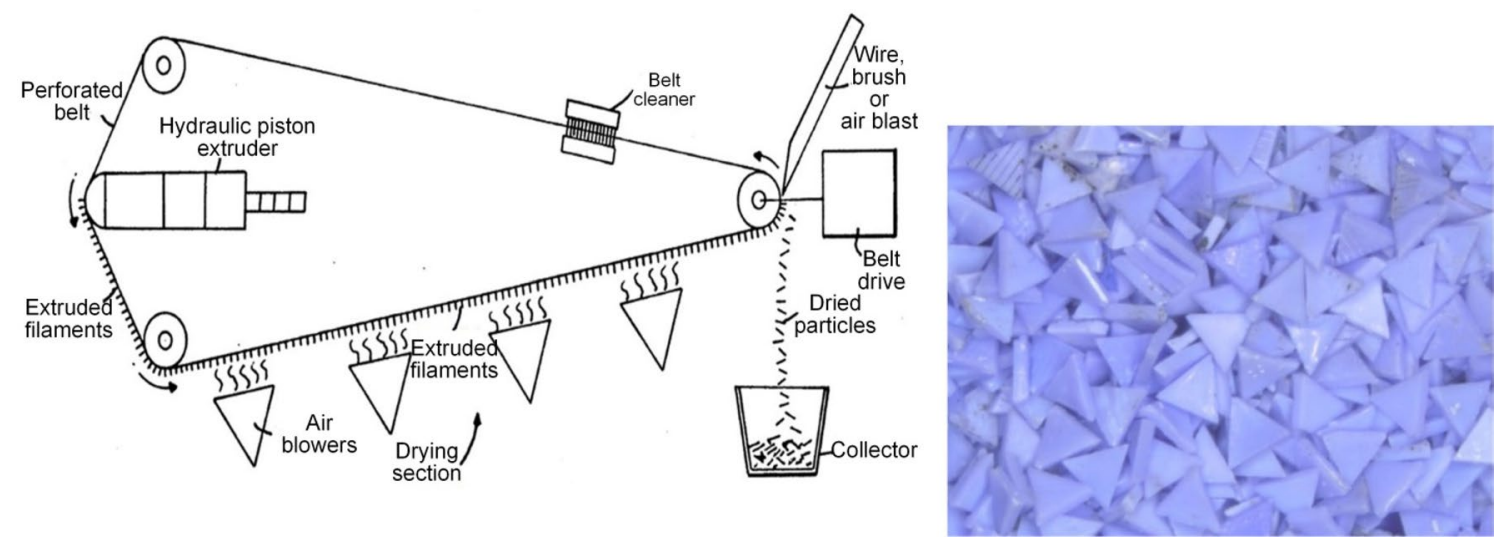

Fig. 15 Manufacturing process for producing extruded ceramic grit and the resulting triangular ceramic grits [36]

Fig. 16 Engineered abrasive grit microstructure showing a standard seeded gel and $\mathbf{b}$ spinel enhanced microstructure [36] Courtesy of Dr. Michael Hitchiner of Saint-Gobain Abrasives (a)

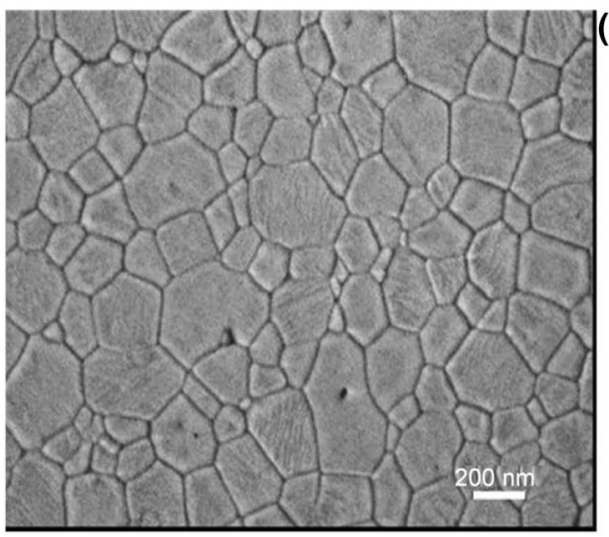

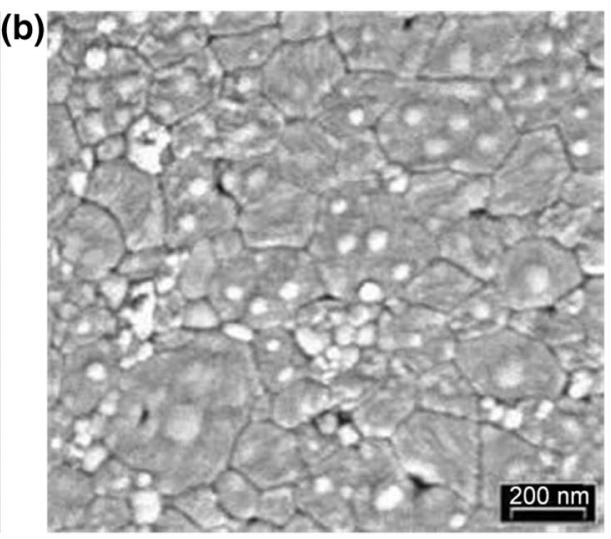


to reduce chip/bond and workpiece/bond friction, which also provides a longer life wheel or one that is much better at profile grinding [50].

\subsection{Agglomerated abrasive grits [36]}

Agglomerated abrasive grits are produced by fusing grits, comminution, agglomeration, sintering, and recomminution of sintered grits. Since the size, shape and chemistry of the crystals are controlled by the initial comminution process, the performance variations in resulting grinding properties are enormous. Also, blending of different (Fig. 17) grits in the same grinding wheel creates the opportunity to combine grits that allows engineers to control microscopic interactions during the grinding of difficult-to-machine workpiece materials such a s those used in the aerospace industries.

Agglomerated grits provide a naturally high level of porosity making them particularly attractive for creep feed grinding applications. In addition, the creation of very sharp and crushed crystals in the initial comminution process combined with controlled strength in the agglomeration binder allows controlled crystals to be pulled out of the grinding wheel to minimize wear flat formation, resulting in very low surface temperatures on heat sensitive materials $[36,50]$. The synthesis of superabrasives that maximizes interaction 1.1 was developed for the processing of difficult-to-machine superalloys. The slower the rate of change of grit morphology due to tribological interactions, the longer grinding process interactions can be sustained at quasi-equilibrium conditions. The abrasive grit is a cutting tool and a tribological slider [27]. Wear by attrition and the generation od wear flats has been extensively studied by Malkin and Cook [28] and with smaller abrasive sizes wear flats are common. Abrasive grits to reduce the sliding interaction between the CBN grit/workpiece interface would require the reduction in the number of grits for small grit sizes. Large wear flats in the diamond grits also rub against the grinding wheel and result in larger wear flats on the abrasive grits in the grinding wheel. CBN grinding wheels used in such a manner result in high normal and tangential threshold forces (due to microscopic interaction 1.3). The cutting process (interaction 1.1) is influenced by the size of the chip generated, generally referred to as the equivalent chip thickness $\left(h_{c}\right)$. In grinding processes $h_{c}$ is the resultant of a number of process parameters (Fig. 18) [29]. An increase in chip thickness leads to more chip formation (lower SCE). The chip thickness in abrasive finishing process can vary over a wide range depending on the nature, size and distribution of the abrasive/workpiece contact area. Several methods have been proposed and deployed to increase the chip thickness, such as increasing the depth of cut (d) as in creep feed grinding, and increasing the work speed $\left(V_{w}\right)$ and the depth of cut simultaneously such as high MRR grinding [30-32]. In ultraprecision grinding processes the number of chips produced per unit time can be increased by increasing the wheel speed, while maintaining a constant $h_{c}$ and this situation been exploited in the development of high speed grinding processes such as high efficiency deep grinding $[33,34]$.

However, all other microscopic interactions need to be monitored and controlled to find the optimum grinding condition. There are many ways to control sliding interactions between grinding wheel and workpiece including higher porosity in grinding wheels [35], controlling the physical construction and chemistry of the interface between abrasive grit and bonding system using high temperature spinel and cordierite phases [36], controlling the wear behavior of the bonding system using lithium feldspars such as petalite, lepidolite and spodumene [37], and methods that influence wheel surface morphology [38] (Fig. 19). Since 2010, the development of engineered grits, shaped and high aspect ratio grits, agglomerated grits and high strength bonding systems has created abrasive products that extend wheel life beyond that of conventional abrasive products (G-ratio between 200 and 500 ), increased MRR in excess of $75 \mathrm{~mm}^{3} / \mathrm{mm}$, reduced the amount of energy used in grinding closer to those used
Fig. 17 Norton Vortex ${ }^{\mathrm{TM}}$ agglomerated alumina grits: a agglomerated grits bonded with Vitrium $3^{\mathrm{TM}}$ bonding system and $\mathbf{b}$ collection of grits bonded with the Vitrium $3^{\text {TM }}$ bonding system $[36,50]$. Courtesy of Dr. Michael Hitchiner of Saint-Gobain Abrasives
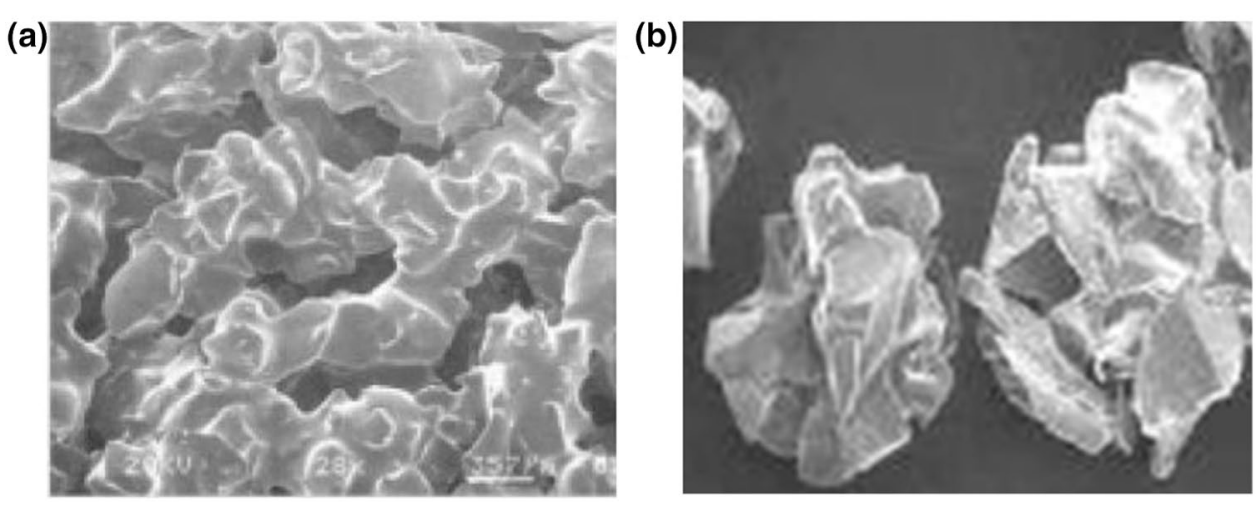


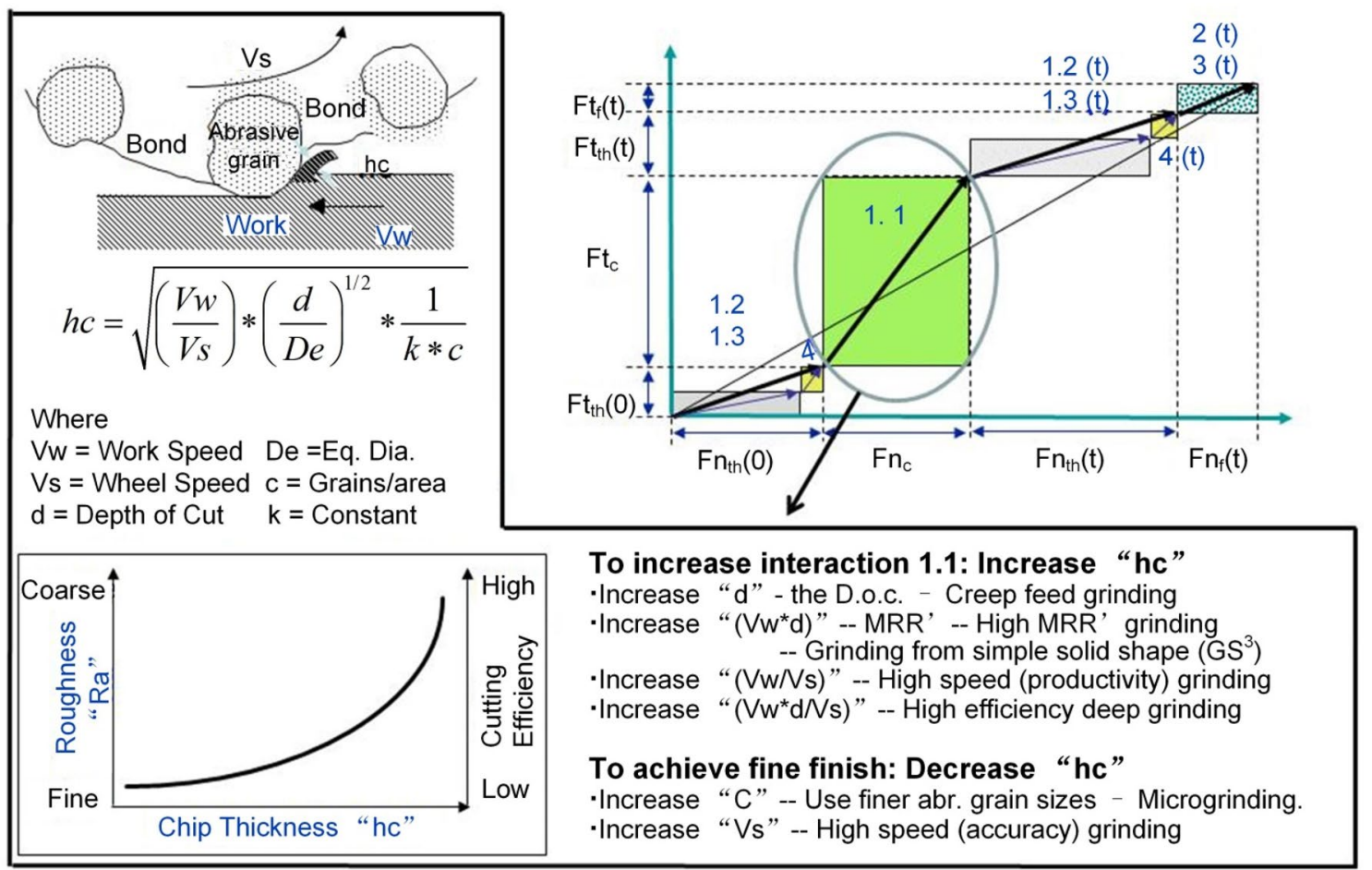

Fig. 18 Grinding product innovations using the chip thickness parameter $\left(h_{c}\right)$ as the variable to control chip loading on abrasive grits [29]. Figure adapted courtesy of Dr. Subramanian, STIMS Institute

Fig. 19 Grinding wheel structure development: a high porosity open structure [35]; b abrasive grit boundary engineering using spinel crystals to prevent dissolution of abrasive grit by the bonding system [36]; c extruded TG2 ${ }^{\text {TM }}$ ceramic grit ( $8: 1$ aspect ratio) in a high strength vitrified bond (Altos ${ }^{\mathrm{TM}}$ ) [37], and d performance data showing power/MRR characteristic of fused alumina and extruded TG ${ }^{\mathrm{TM}}$ ceramic grit in a vitrified bond [50]. Images courtesy of Dr. Michael Hitchiner and Roland Wakefield of Saint-Gobain Abrasives (a)

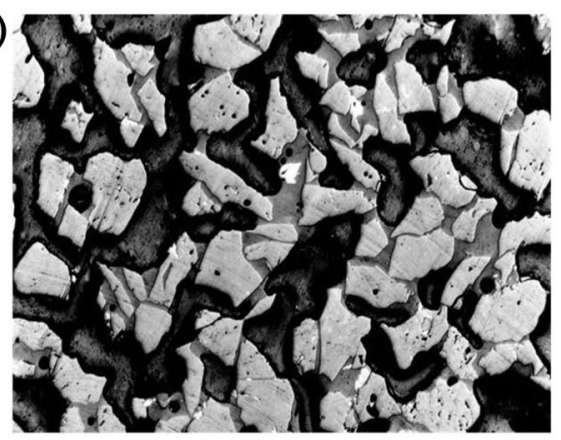

(b)

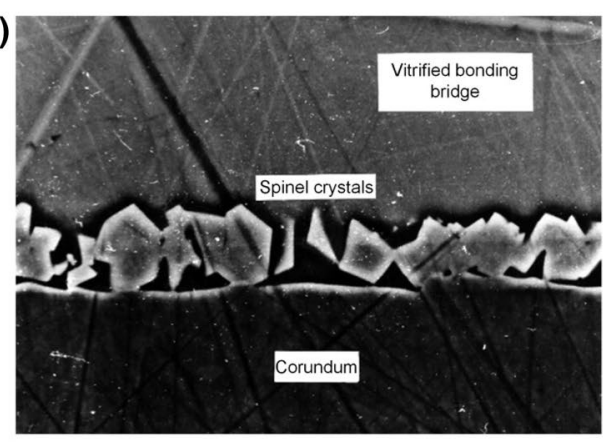

(c)

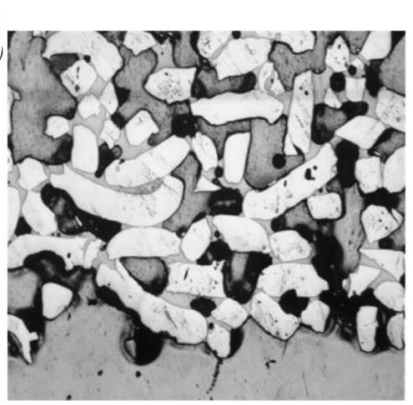

(d) $\mathrm{P}[\mathrm{kW}]$

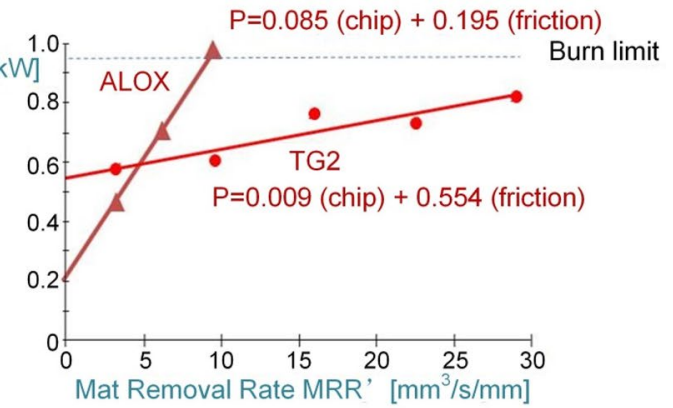

in hobbing processes, and can be dressed using standard diamond dressing tools [39-50].

The next step in the evolution of abrasive products based on data provided by monitoring and deriving information associated with microscopic interactions will focus on using techniques from the nanotechnology realm to understand and develop products by manipulating atoms, or collections of atoms, in order to further 
enhance the performance of abrasive products in ultraprecision machining systems. Current techniques including contact atomic force microscopy, scanning tunneling microscopy, soft lithography, ion beam machining, 3-D printing and variants offer a great deal of hope in developing the next generation of abrasive grits and associated products $[51,52]$.

\section{Conclusions}

The role of materials science in metal removal is critical in the sense of developing the next generation of abrasive products and tools necessary for ultraprecision machining/grinding of advanced materials. By designing abrasive grits and bonding systems to control the rate of heat dissipation, a significant impact on grinding difficult-to-machine superalloys and related materials will be achieved. The control of shear strain rates will certainly aid in the efficient removal of material from superalloys and is an avenue where controlling atomic activity in the first few monolayers of the abrasive grit should be initially directed. Incorporating elements such as sulphur and chlorine in the monolayers of abrasive grit and workpiece material will certainly help to create the conditions where workpiece materials become locally brittle (promoting cutting interaction 1.1) and low temperature metal salts melt to create a lubricious film between abrasive grit and workpiece material (minimizing the deleterious effects of sliding interactions 1.2 and 1.3).

In practice, it is possible to measure the grinding power and decompose it into $P_{t h}(t=t), P_{t h}(t=t), P_{c}$ and $P_{f}(t=t)$ power components that relate to tribological interactions at the microscale for many different abrasive processes and workpiece/grit combinations. Force ratios shown in Table 2 can be used to estimate real-time grinding forces to find the total grinding force. Computer-based iteration tools to estimate force components from measurements of grinding power are attractive especially when looking at which interaction mechanism is dominant in the grinding process. Together with an understanding of how materials structure fracture, new products can be developed that generate surfaces and forms that are fit for function.

In conclusion, by combining advanced computational techniques and the ability to manipulate atoms and collections of atoms, the future development of processes and tools for ultraprecision machining processes such as grinding, lapping, CMP, etc., is very bright indeed.

Acknowledgements The author acknowledges provision of images and permission to reproduce from Dr. Subramanian, STIMS Institute, Dr. Michael Hitchiner and Roland Wakefield of Saint-Gobain
Abrasives, Karen Blundell, Liverpool John Moores University, and Professor Viktor Astakhov of Michigan State University, USA.

\section{Compliance with ethical standards}

Conflict of interest The author declares that he has no conflicts of interest to report regarding this paper. The author is not connected in any way to any abrasive manufacturer or retailer of such products and no funding was provided by any abrasive manufacturer regarding this review of the state-of-the-art.

\section{References}

1. Subramanian K et al (2017) Microscopic interactions in surface generation processes using abrasive tools. ASME J Manuf Sci Eng 139:1-17

2. Subramanian $\mathrm{K}$ (2015) Role of process science in manufacturing. http://stimsinstitute.com/2014/12/26/stims-institute-offers-itsvision-of-21st-century-manufacturing/. Accessed 2 Aug 2019

3. Shaw MC (2004) Metal cutting principles, 2nd edn. Clarendon Press, Oxford, pp 26-61

4. Wolak J, Finnie I (1967) A comparison of stress-strain behaviors in cutting and high strain rate compression tests. In: Advances in machine tool design and research 1967: proceedings of the 8th international MTDR conference, $\mathrm{p} 246$

5. Suh NP (1986) Tribophysics. Prentice-Hall, Englewood Cliifs

6. Subramanian K (1990) Finishing using multiple cutting edges. ASM Handbook 5:107

7. Malkin S, Guo C (2008) Grinding technology: theory and application of machining with abrasives. Industrial Press, New York, pp 319-321

8. Lindsey RP (1986) Principles of grinding. In: King R, Hahn R (eds) Handbook of modern grinding technology. Chapman and Hall, New York, pp 30-71

9. Linke BS et al (2017) Grinding energy modelling based on friction, plowing and shearing. ASME J Manuf Sci Eng 139:1-11

10. Xiao G, Malkin S, Danai K (1992) Intelligent control of cylindrical plunge grinding. In: American control conference, pp 391-399

11. Astakhov VP (2006) Tribology of metal cutting, 1st edn. Elsevier Science, Oxford, p 392

12. Long $Y$, Huang $Y$, Sun $X$ (2010) Combined effect of flank and crater wear on cutting force modeling in orthogonal machining-Part II. Mach Sci Technol 14(1):31

13. Bowden FP, Tabor D (1939) The area of contact between stationary and moving surfaces. Proc R Soc A169:319-341

14. Malkin S, Guo C (2008) Grinding technology: theory and application of machining with abrasives. Industrial Press, New York, pp 123-124

15. Bhushan B (2013) Principles and applications of tribology, Chapter 5, 2nd edn. Wiley, New York, pp 271-320

16. Foster M, Ramanan N (1997) Wear mechanisms of electroplated $\mathrm{CBN}$ wheels during the grinding of $\mathrm{Ni}$ base alloys with aqueous based coolant. In: 2nd international machining and grinding. Conference, SME, Sep. 8-11, 1997, Dearborn, MI, USA

17. Subramanian $\mathrm{K}$ (2016) Bringing the science to shop floor manufacturing. Efficient Manufacturing, Feb 2016, pp 42-46. https ://www.industr.com/en/EMMagazine/_storage/asset/19849 59/storage/master/file/13764293/EM\%20Feb\%202016.pdf. Accessed 2 Aug 2019

18. Vairamuthu R, Bhushan BM, Srikanth R, Babu NR (2016) Performance enhancement of cylindrical grinding process with a portable diagnostic system. Procedia Manuf 5:1320-1336 
19. Malkin S, Guo C (2008) Grinding technology: theory and application of machining with abrasives. Industrial Press, New York, $p$ 21

20. Csillag F (2012) Engineered to cut above all. Saint-Gobain Symposium on Grinding Science, Northborough R\&D Laboratory, Saint-Gobain Norton Abrasives, Massachusetts, USA, November 8th 2012

21. Saint-Gobain Abrasives (2019) AZ-40 for Coated Abrasives Product Codes: 1565 and 1575. Saint-Gobain Abrasive Materials. https://www.abrasivematerials.saintgobain.com/sites/imdf. abrasivematerials.com/files/az40_for_coated_abrasives_70376 .pdf. Accessed 2 Aug 2019

22. Rowse RA, Watson GR (1975) Zirconia-alumina abrasive grit and grinding tools. U.S. Patent No. 3891408

23. Haynes DG (1991) Alumina bonded abrasive for cast iron. U.S. Patent No. 5139539

24. Saint-Gobain Abrasive Materials (2019) Cerpass DGE from https://www.abrasivematerials.saint-gobain.com/sites/imdf. abrasivematerials.com/files/cerpass_dge_for_bonded_abras ive_tools_70357.pdf. Accessed 2 Aug 2019

25. Diamond Innovations (2019) Borazon CBN from http://myacc ount.diamondinnovations.com/en/product/mbs/cbn/b.htm. Accessed 2 Aug 2019

26. Hahn RS, Lindsay RP (1972) The principles of grinding. In: The science of ceramic machining and surface finishing: proceedings of a symposium sponsored by the American Ceramic Society, the Office of Naval Research and the National Bureau of Standards, Maryland, $\mathrm{p} 70$

27. Subramanian K, Lindsay RP (1992) A systems approach for the use of vitrified bonded superabrasive wheels for precision production grinding. J Manuf Sci Eng 114(1):41-52

28. Malkin S (1971) Cook NH (1971) The wear of grinding wheelsPart 1 Attritious wear. ASME J Eng Ind 93:1120-1128

29. Malkin S, Guo C (2008) Grinding technology: theory and application of machining with abrasives. Industrial Press, New York, pp 54-60

30. Andrew C, Howes TD, Pearce TRA (1985) Creep feed grinding. Holt, Rinehart and Winston Ltd., Sussex, pp 1-2

31. Wang S, Li CH (2012) Application of high-efficiency abrasive process. Int J Adv Sci Technol 47:1320-1336

32. Subramanian K, Tricard M (1995) CNC grinding from simple solid shape-a rapid response strategy. SME Technical Paper Series (Paper \# MR95-269)

33. Klocke $F$, Brinksmeier $E$, Evans $C$, Howes $T$, Inasaki I, Minke $E_{\text {, }}$ Tönshoff HK, Webster JA, Stuff D (1997) High-speed grindingfundamentals and State of the Art in Europe, Japan and USA. Ann CIRP 46(2):715-724

34. Batako ADL, Morgan MN, Rowe W (2013) High efficiency deep grinding with very high removal rates. Int J Adv Manuf Technol 66(9-12):1367-1377

35. Salmon SC (2004) Creep-feed grinding is surprisingly versatile. Manuf Eng 133(5):59-64

36. Jackson MJ, Hitchiner MP (2014) High performance grinding and advanced cutting tools, Springer Briefs in Applied Sciences and Technology. Springer Nature, New York, pp 45-94
37. Benes J (2007) All about abrasives: an array of abrasive-grit types meets any grinding or finishing requirement. American Machinist. http://americanmachinist.com/features/all-about-abrasives. Accessed 2 Aug 2019

38. Marinescu ID, Rowe WB, Dimitrov B, Ohmori H (2012) Tribology of abrasive machining processes, Chapter 11. William Andrew Elsevier, Amsterdam, pp 369-456

39. Subramanian K, Jain A, Rajagopal V, Bushan BM (2015) Tribology as an enabler for innovation in surface generation processes. In: Proceedings of the ASME 2015 international mechanical engineering congress and exposition, IMECE 2015-52952, Nov 13-19, 2015, Houston, Texas, USA

40. Nakajima T, Uno Y, Fujiwara $T$ (1989) Cutting mechanism of fine ceramics with a single point diamond. Precis Eng 11(1):19-25

41. Subramanian K, Ramanath S, Tricard M (1997) Mechanisms of material removal in the precision production grinding of ceramics. J Manuf Sci Eng 119(4A):509-519

42. Subramanian K (1988) Precision finishing of ceramic components with diamond abrasives. Ceram Bull 67(6):1026-1029

43. Ramanath S, Kuo SY, Willston WH, Buljan ST (2000) Method for grinding precision components. U.S. Patent No. 6019668

44. Lindsay RP (1999) Fundamentals of precision production. In: Grinding, machining and metalworking conference, $S M E$, Detroit, USA, pp 1-78

45. Subramanian K, Webster JW, Caputa P (2010) Method for grinding complex shapes. U.S. Patent No. 7708619 B2, Assignee: Saint-Gobain Abrasives, Worcester, MA (US)

46. Besse JR, Graham DC, Subramanian K, Ramanath S, Lamoureux MA (2014) Abrasive tool and a method for finishing complex shapes in workpieces. U.S. Patent No. 8911283

47. Besse JR, Graham D (2009) Grinding turbine rotors has advantages. Modern Machine Shop. http://www.mmsonline.com/ articles/grinding-turbine-rotors-has-advantages. Accessed 2 Aug 2019

48. Willcutt R (2019) Grinding big gears from blanks, Article From: 3/2/2015 Modern Machine Shop. http://www.mmsonline.com/ articles/grinding-big-gears-from-blanks. Accessed 2 Aug 2019

49. Hitchiner $M$, Graham D, Plainte $P$ (2013) Advances in abrasive technology for grinding gears from solid. Gear Solutions. http:// www.gearsolutions.com/article/detail/6368/advances-in-abras ive-technology-for-grinding-gears-from-solid\#comments. Accessed 2 Aug 2019

50. Hitchiner $M$ (2015) Precision grinding faster than machining. In: United Grinding North America Grinding conference, Miamisburg. OH, USA, September 16-17, 2015, pp 1-32

51. Ahmed W, Jackson MJ (2015) Emerging nanotechnologies for manufacturing, 2nd edn. Elsevier, New York, pp 1-551

52. Jackson MJ, Ahmed W (2018) Micro and nanomanufacturing, vol II. Springer-Nature, New York, pp 1-570

Publisher's Note Springer Nature remains neutral with regard to jurisdictional claims in published maps and institutional affiliations. 